\title{
MET is required for the recruitment of anti-tumoural neutrophils
}

\author{
Veronica Finisguerra ${ }^{1,2}$, Giusy Di Conza ${ }^{1,2}$, Mario Di Matteo ${ }^{1,2}$, Jens Serneels ${ }^{1,2}$, Sandra Costa $^{1,2,3,4}$, A. A. Roger Thompson ${ }^{5}$, \\ Els Wauters ${ }^{6,7,8}$, Sarah Walmsley ${ }^{5} \uparrow$, Hans Prenen ${ }^{9}$, Zvi Granot ${ }^{10}$, Andrea Casazza ${ }^{1,2}$ \& Massimiliano Mazzone ${ }^{1,2}$
}

\begin{abstract}
Mutations or amplification of the $M E T$ proto-oncogene are involved in the pathogenesis of several tumours ${ }^{1-4}$, which rely on the constitutive engagement of this pathway for their growth and survival ${ }^{1,5}$. However, MET is expressed not only by cancer cells but also by tumour-associated stromal cells, although its precise role in this compartment is not well characterized ${ }^{6-11}$. Here we show that MET is required for neutrophil chemoattraction and cytotoxicity in response to its ligand hepatocyte growth factor (HGF). Met deletion in mouse neutrophils enhances tumour growth and metastasis. This phenotype correlates with reduced neutrophil infiltration to both the primary tumour and metastatic sites. Similarly, Met is necessary for neutrophil transudation during colitis, skin rash or peritonitis. Mechanistically, Met is induced by tumourderived tumour necrosis factor (TNF)- $\alpha$ or other inflammatory stimuli in both mouse and human neutrophils. This induction is instrumental for neutrophil transmigration across an activated endothelium and for inducible nitric oxide synthase production upon HGF stimulation. Consequently, HGF/MET-dependent nitric oxide release by neutrophils promotes cancer cell killing, which abates tumour growth and metastasis. After systemic administration of a MET kinase inhibitor, we prove that the therapeutic benefit of MET targeting in cancer cells is partly countered by the pro-tumoural effect arising from MET blockade in neutrophils. Our work identifies an unprecedented role of MET in neutrophils, suggests a potential 'Achilles' heel' of MET-targeted therapies in cancer, and supports the rationale for evaluating anti-MET drugs in certain inflammatory diseases.
\end{abstract}

To ensure Met deletion in the immune system only, we took advantage of the Tie2:Cre deleter that excises floxed genes in both bone marrow and endothelial cells ${ }^{12}$, and we reconstituted lethally irradiated C57BL/6 wild-type (WT) mice with bone marrow cells from Tie2;Met $t^{w t / w t}(\mathrm{WT})$ or Tie2;Met $t^{f l f l}$ (knockout $(\mathrm{KO})$ ) mice (Extended Data Fig. 2a), producing WT $\rightarrow \mathrm{WT}$ or $\mathrm{KO} \rightarrow \mathrm{WT}$ mice, respectively. Compared to WT $\rightarrow$ WT controls, both growth and metastatic burden of subcutaneous LLC lung carcinomas were boosted in $\mathrm{KO} \rightarrow \mathrm{WT}$ mice (Fig. 1a-g), with reduced tumour apoptosis and necrosis, increased proliferation, but comparable vessel parameters and hypoxia (Extended Data Fig. 2b-r). A similar induction in tumour growth and metastasis was observed in non-irradiated $\mathrm{KO}$ versus WT mice (Extended Data Fig. 2s-u), but tumour growth, as well as the vascular features, were comparable in $\mathrm{WT} \rightarrow \mathrm{WT}$ versus $\mathrm{WT} \rightarrow \mathrm{KO}$ chimaeras, displaying Met deletion in endothelial cells only (Extended Data Fig. 2o-r, v). Thus, Met deletion in immune cells favours cancer growth and metastasis.

Blood counts and percentage of circulating blood cell subsets did not change in $\mathrm{WT} \rightarrow \mathrm{WT}$ and $\mathrm{KO} \rightarrow \mathrm{WT}$ mice, either at baseline or upon
LLC tumour engraftment (Extended Data Fig. 3a-e and Extended Data Tables 1,2). Notably, $\mathrm{KO} \rightarrow \mathrm{WT}$ mice displayed reduced numbers of tumour-infiltrating $\mathrm{CD} 45^{+}$leukocytes and, among all the different subpopulations, only Ly6G ${ }^{+}$tumour-associated neutrophils (TANs) were strongly reduced in $\mathrm{KO} \rightarrow \mathrm{WT}$ versus $\mathrm{WT} \rightarrow \mathrm{WT}$ mice at any time point (Fig. 1h-j and Extended Data Fig. 3f-k). Similarly, lungs from $\mathrm{KO} \rightarrow$ WT tumour-bearing mice contained fewer $\mathrm{CD} 45^{+}$leukocytes with decreased $\mathrm{Ly}_{6 \mathrm{G}}{ }^{+}$neutrophil infiltration, whereas the number of F4/80 ${ }^{+}$macrophages was comparable (Fig. $1 \mathrm{k}-\mathrm{m}$ and Extended Data Fig. 31, m). Furthermore, reconstitution of Met in neutrophils only ${ }^{13}$ (Extended Data Fig. 4a, b) was sufficient to rescue their recruitment and to hinder tumour growth and metastasis in $\mathrm{KO} \rightarrow \mathrm{WT}$ mice (Fig. $1 \mathrm{n}-\mathrm{q})$. Vice versa, restricted deletion of Met in neutrophils (Mrp8;Met $t^{f / f l}$ ) by the neutrophil-specific Mrp8:Cre line ${ }^{13}$ (Extended Data Fig. 4c, d) led to enhanced tumour growth and dissemination, and marked TAN reduction, as in $\mathrm{KO} \rightarrow \mathrm{WT}$ chimaeras (Fig. $1 \mathrm{r}-\mathrm{u}$ and Extended Data Fig. 4e). These results indicate that MET is required for recruiting anti-tumoural neutrophils.

To extend our findings to other tumour types, we proved that Met deletion in the haematopoietic system increased the growth of (1) orthotopic T241 fibrosarcomas and B16F10 melanomas, (2) spontaneous mammary tumours in MMTV-PyMT ${ }^{+}$transgenic mice, (3) $\mathrm{H}$-Ras(G12V)- and c-Myc-driven hepatocellular carcinomas (HCCs), and (4) chemically induced colorectal cancers (CRCs) (Fig. 2a-j and Extended Data Fig. 5a, b). Furthermore, lung colonization of B16F10 melanoma cells (from either the primary tumour or after cancer cell intravenous injection) and of MMTV-PyMT ${ }^{+}$breast tumours was boosted in Met KO chimaeras (Fig. 2k, 1 and Extended Data Fig. 5c). In all these tumour types, Met KO TANs were fewer than WT TANs (Fig. $2 \mathrm{~m}$ and Extended Data Fig. 5d, e). Interestingly, during chronic bowel inflammation (preceding CRC formation), neutrophil but not macrophage infiltration of the colon was also abated by haematopoietic Met deletion, but this reduction did not impinge on colitis severity (Extended Data Fig. 5f-i). B16F10 melanomas and HCCs displayed enhanced tumour growth (and metastasization) as well as reduced TAN infiltration in Mrp8;Met $t^{f l / f l}$ versus Mrp8;Met $t^{\text {wt/wt }}$ mice (Fig. 2n-q). Conversely, orthotopic Panc02 carcinomas grew and metastasized similarly in both $\mathrm{WT} \rightarrow \mathrm{WT}$ and $\mathrm{KO} \rightarrow \mathrm{WT}$ mice, and TAN infiltration did not change (Extended Data Fig. 5j-1). However, these tumours produced little HGF compared to LLC tumours (Extended Data Fig. 5m, n). In general, plasma and intratumour HGF did not differ between genotypes (Extended Data Fig. 5o, p). In sum, Met deficiency in neutrophils promotes the progression of different (HGF-secreting) tumours.

Systemic treatment of WT mice carrying B16F10 melanomas (which are dependent on $\mathrm{MET}^{14}$ ) with three different MET tyrosine-kinase

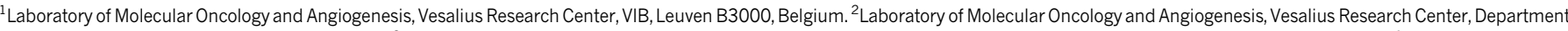
of Oncology, KU Leuven, Leuven B3000, Belgium. ${ }^{3}$ Life and Health Sciences Research Institute (ICVS), School of Health Sciences, University of Minho, $4710-057$ Braga, Portugal. ${ }^{4}$ ICVS/3B's - PT

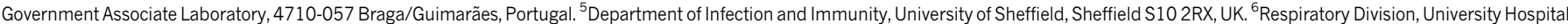

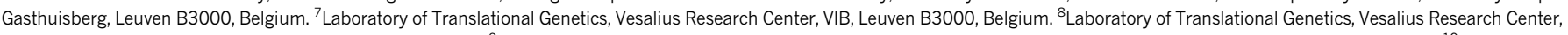

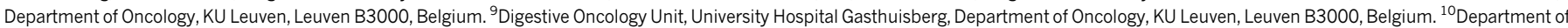

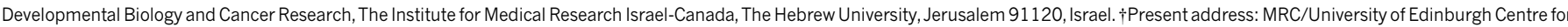
Inflammation Research, The Queen's Medical Research Institute, University of Edinburgh, Edinburgh EH16 4TJ, UK. 

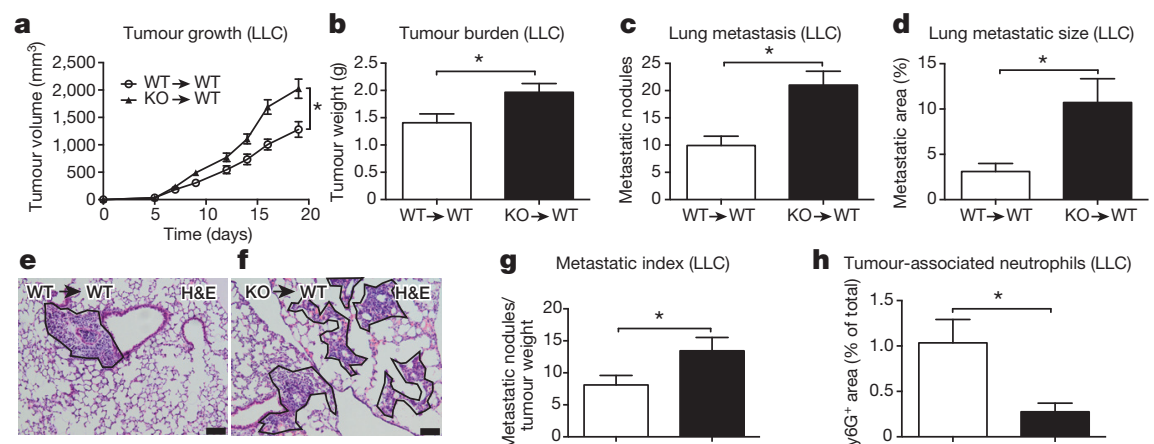

g Metastatic index (LLC)
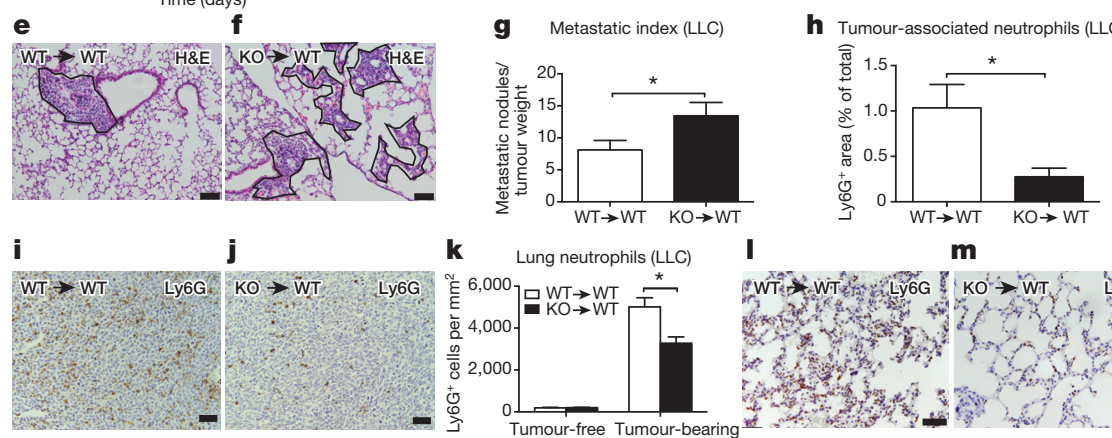

k Lung neutrophils (LLC)
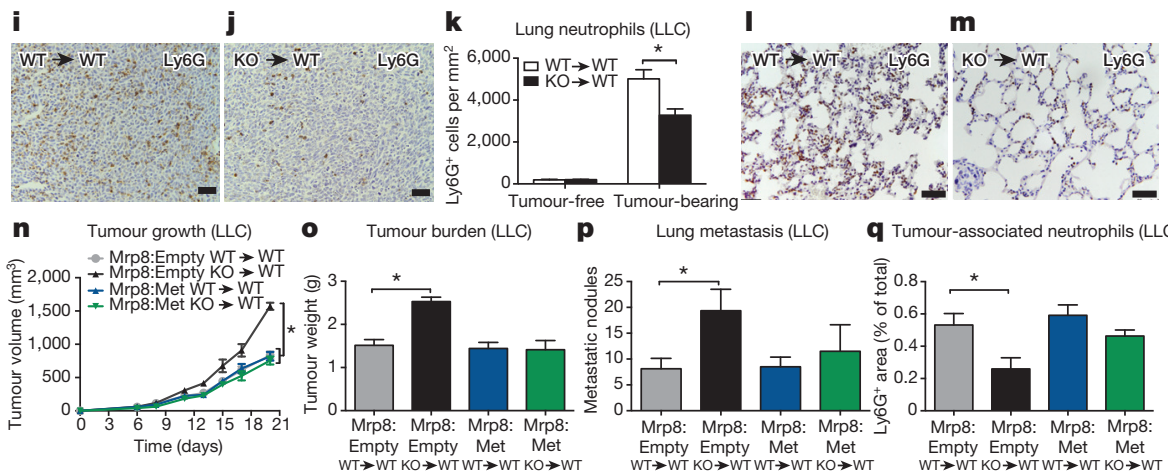

Lung metastasis (LLC)
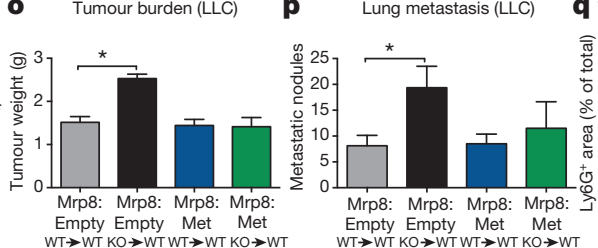

Tumour-associated neutrophils (LLC) WT $\rightarrow$ WT KO $\rightarrow$ WT WT $\rightarrow$ WT $\underset{\text { Empty Empty Met Met }}{\text { WT } \rightarrow \text { WT KO } \rightarrow \text { WT }}$

t Lung metastasis (LLC)

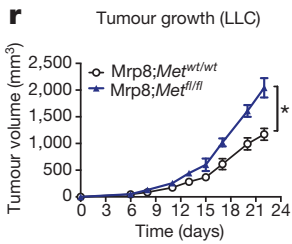

s Tumour burden (LLC)
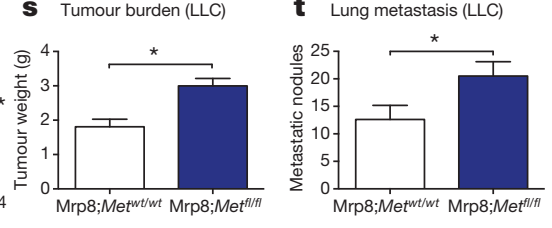

Mrp8;Met ${ }^{\text {wt }}$ wt Mrp8;Met

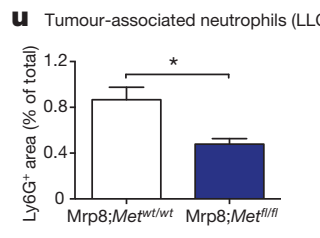

Figure $1 \mid$ Met deficiency inhibits neutrophil recruitment to tumour and metastatic site. a-g, LLC tumour growth (a), weight (b), lung macrometastases (c), metastatic area

(d), representative images of haematoxylin and eosin (H\&E)-stained lung sections (e, f), and metastatic index $(\mathbf{g})$ in $\mathrm{WT} \rightarrow \mathrm{WT}$ and $\mathrm{KO} \rightarrow \mathrm{WT}$ chimaeras. Data combine three independent experiments; total mice: $\mathrm{WT} \rightarrow \mathrm{WT}, 23$;

$\mathrm{KO} \rightarrow \mathrm{WT}, 26 . \mathbf{h}-\mathbf{m}$, Neutrophil quantification and representative images on Ly6G-stained LLC tumour sections $(\mathbf{h}-\mathbf{j})$ or on lung sections from tumour-free and tumour-bearing mice

(k) represented in $\mathbf{l}, \mathbf{m}$. Data in $\mathbf{h}$ are representative of four independent experiments (6 mice per condition per experiment). Data in $\mathbf{k}$ combine three independent experiments; total mice: tumour-free, 10 per condition; tumour-bearing, 15 per condition. $\mathbf{n}-\mathbf{q}$, LLC tumour growth (n), tumour weight (o), lung macrometastases $(\mathbf{p})$, and TAN quantification $(\mathbf{q})$ in WT $\rightarrow \mathrm{WT}$ and $\mathrm{KO} \rightarrow$ WT control chimaeras (Mrp8:Empty) or upon neutrophil-specific Met reconstitution (Mrp8:Met). Data combine two independent experiments; total mice, 10 per condition. $\mathbf{r}-\mathbf{u}$, LLC tumour growth (r), tumour weight (s), lung macrometastases $(\mathbf{t})$, and TAN quantification (u) upon neutrophil-specific Met deletion $\left(\right.$ Mrp8;Met $\left.t^{f l f l}\right)$ and in controls (Mrp8;Met $\left.t^{w t / w t}\right)$. Data combine two independent experiments; total mice, 13 per condition. $* P<0.05$. Scale bars: $100 \mu \mathrm{m}(\mathbf{e}, \mathbf{f}) ; 50 \mu \mathrm{m}(\mathbf{i}, \mathbf{j}, \mathbf{l}, \mathbf{m})$. Graphs show mean \pm standard error of the mean (s.e.m.) inhibitors (PF-04217903, INCB28060 and JNJ-38877605), strongly reduced TAN recruitment (Extended Data Fig. 5q). We then compared MET silencing in cancer cells versus systemic MET inhibition. Systemic administration of PF-04217903 decreased the weight and volume of B16F10 melanomas by $36 \%$ and $54 \%$, respectively. Instead, MET knockdown in cancer cells only, led to $58 \%$ and $75 \%$ inhibition of tumour growth and volume (Fig. 2r, s and Extended Data Fig. 5r). However, the combination of these two strategies was not synergic but dampened tumour inhibition to the same level as observed with PF-04217903 alone (Fig. 2r, s). TAN inhibition by PF-04217903 was comparable in both Met-silenced and scrambled B16F10 melanomas (Fig. 2t). These data unveil how the therapeutic benefit of systemic MET inhibition is partly blunted by the blockade of anti-tumoural neutrophils.

To date, MET expression in neutrophils has been poorly documented $^{11}$. We thus measured MET levels in circulating or tumour-infiltrating neutrophils. Circulating $\mathrm{Ly}_{6 \mathrm{G}}{ }^{+}$cells from healthy mice expressed low MET, but these levels were increased in circulating neutrophils from LLC-tumour-bearing mice and even further in TANs (Fig. 3a, b and Extended Data Fig. 6a). Similarly, neutrophils isolated from non-small-cell lung tumours displayed much higher MET levels than in the healthy tissue (Fig. 3c).

Co-culture with interleukin (IL)-1 $\alpha$ pre-activated endothelium as well as stimulation with tumour- or cancer-cell-conditioned medium (TCM or CCM, respectively) promoted MET expression in both mouse and human neutrophils (Fig. 3d-g). In a biased approach $^{15-17}$, we found that TNF- $\alpha$ and lipopolysaccharide (LPS) (but not IL-1 $\alpha, \mathrm{HGF}$, or hypoxia) induced MET expression in both mouse and human neutrophils (Fig. 3h and Extended Data Fig. 6b-e; data not shown). TNF- $\alpha$-mediated MET induction required TNFR1 and subsequent nuclear factor (NF)- $\kappa$ B activation (Fig. $3 \mathrm{i}-\mathrm{k}$ ). TNF- $\alpha$ alone was not able to trigger either MET phosphorylation or HGF release in neutrophils (Extended Data Fig. 6f-h).

Silencing of endothelial-cell-borne TNF- $\alpha$ (which is 250-fold increased upon stimulation with IL-1 $\alpha$; Extended Data Fig. 6i), knockout of neutrophil-borne TNFR1 (but not of TNFR2), and pharmacological blockade of TNF- $\alpha$ with the TNF- $\alpha$-trap Enbrel, prevented $M E T$ induction in mouse or human neutrophils upon co-culture with activated endothelial cells or exposure to TCM/CCM (Fig. 31 and Extended Data Fig. 6j-m). Finally, systemic administration of Enbrel in LLC-tumour-bearing mice diminished MET expression in neutrophils as well, resulting in their reduced recruitment to the tumour (Fig. $3 \mathrm{~m}, \mathrm{n}$ ). Although MET is scarcely expressed in naive neutrophils, it is strongly induced by inflammatory stimuli.

Mechanistically, impaired TAN accumulation after Met inactivation was not due to cell death as assessed in LLC tumours and in culture, both at baseline and under LPS stimulation, with or without HGF (Extended Data Fig. 7a-e), but rather to a defect in neutrophil recruitment from the blood. Indeed, also in the case of acute inflammation, $\mathrm{Met} \mathrm{KO}$ neutrophils displayed reduced exudation to the skin or to the peritoneal cavity (Fig. 4a-d and Extended Data Fig. 8a, b). Macrophage and lymphocyte recruitment did not change (Fig. $4 \mathrm{~d}$ and Extended Data Fig. 8c, d). Vice versa, recombinant HGF recruited WT neutrophils inside subcutaneous air pouches with similar efficacy to the neutrophil chemoattractant CXCL1 (Fig. 4e and Extended Data Fig. 8e). In contrast, Met KO neutrophils did not migrate towards HGF, although their response to CXCL1 was preserved (Fig. 4e and Extended Data Fig. 8e). Mirroring this approach, an anti-HGF blocking antibody ${ }^{18}$ prevented neutrophil infiltration to tumours and inflamed skin (Fig. 4f).

We then tested the relevance of MET for neutrophil migration. Stimulation of WT neutrophils with HGF promoted their adhesion and chemotaxis through an activated endothelium whereas Met KO 

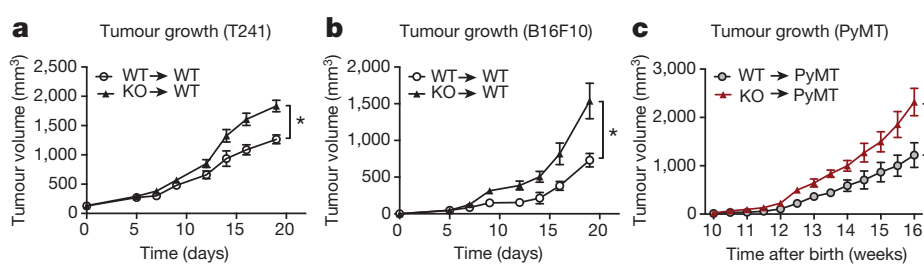

d Tumour burden (HCC)
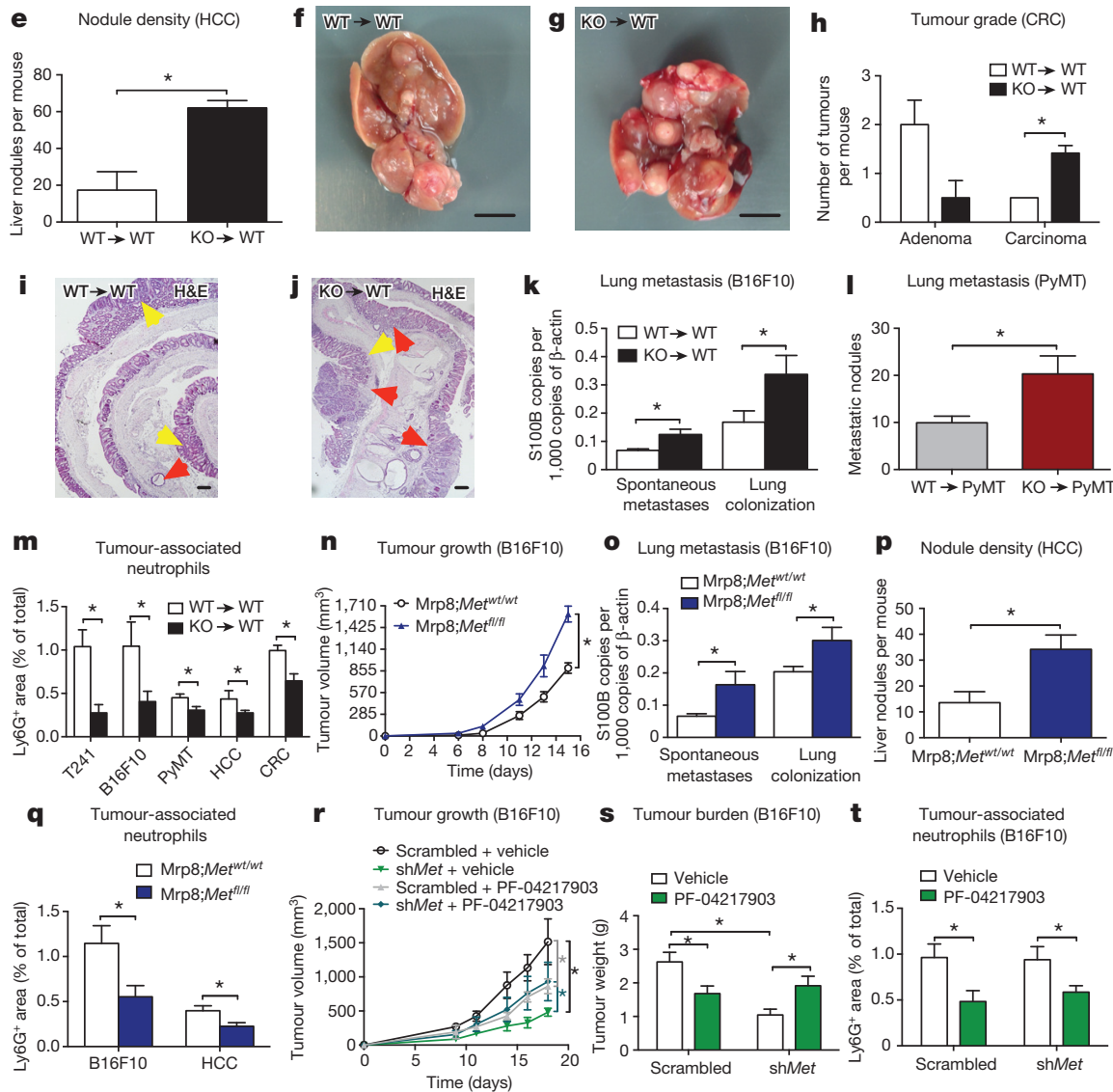

- Lung metastasis (B16F10)

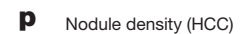

Lung metastasis (B16F10)

P Nodule density (HCC)

E 1,710 - - Mrp8:Met

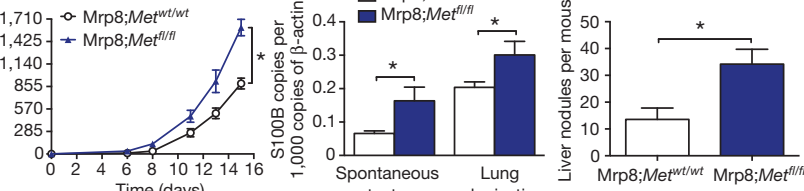
metastases colonization

Mrp8:Metwt/wt Mrp8:Met/l/t

S Tumour burden (B16F10) $\mathbf{t}$

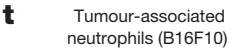

neutrophils (B16F10)

$\square$ Vehicle

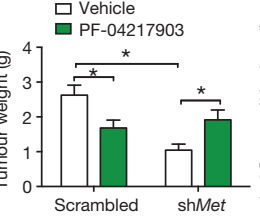

$\square$ Vehicle

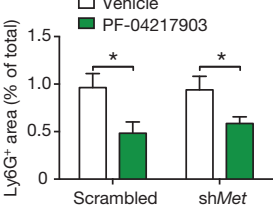

Figure $2 \mid$ Met deficiency in haematopoietic cells fosters progression of several tumour types. a-c, Growth of T241 fibrosarcomas (a), B16F10 melanomas (b) and PyMT-driven breast tumours (c). Data in $\mathbf{a}, \mathbf{b}$ combine two independent experiments; total mice, 14 per condition (a); 8 per condition (b). Data in c combine three independent experiments; total mice: $\mathrm{WT} \rightarrow$ PyMT, 13; KO $\rightarrow$ PyMT, 16. d-g, Liver weight (d), nodules (e), and images (f, $\mathbf{g})$ after H-Ras (G12V)/c-Myc-driven HCC $(n=4$ mice per condition). $\mathbf{h}-\mathbf{j}$, Quantification (h) on H\&E-stained bowel sections (i, j) of colon adenomas (yellow arrowheads) and carcinomas (red arrowheads) after administration of azoxymethane (AOM) and dextran sodium sulfate (DSS). Data combine two independent experiments; total mice, 10 per condition. k, Spontaneous lung metastases from B16F10 tumours or lung colonization after B16F10 intravenous injection. Data combine two independent experiments; total mice, 8 per condition. 1, Lung macrometastases from PyMT tumours. Data combine three independent experiments; total mice:
$\mathrm{WT} \rightarrow \mathrm{PyMT}, 13 ; \mathrm{KO} \rightarrow$ PyMT, 16. m, TAN quantification in T241, B16F10, PyMT, HCC and CRC tumour tissues. Total mice: T241 and CRC, 10 per condition; B16F10, 8 per condition, combining two experiments;

$\mathrm{WT} \rightarrow$ PyMT, 13; KO $\rightarrow$ PyMT, 16, combining three experiments; HCC, 4 per condition (one experiment). n, o, B16F10 tumour growth (n), spontaneous metastases and lung colonization (o) in Mrp8;Met $t^{w t / w t}$ and Mrp8;Met $t^{f l f l}$ mice. Data combine two independent experiments; total mice: Mrp8;Met ${ }^{w t / w t}, 12$; Mrp8;Met ${ }^{f l / f l}$, 8. p, Liver nodules in Mrp8;Met ${ }^{w t / w t}$ and Mrp8;Met ${ }^{f l / f l}$ HCCbearing mice. Total mice, 7 per condition. q, TAN quantification in B16F10 tumours (total mice, 8 per condition) or HCCs (total mice, 7 per condition). $\mathbf{r}-\mathbf{t}$, Tumour growth (r), weight (s) and TANs in short hairpin RNA (shRNA) Met-silenced (shMet) and scrambled B16F10 tumours after PF-04217903 or vehicle treatment. Data combine two independent experiments (total mice, 11 per condition for scramble; 14 per condition for shMet). $* P<0.05$. Scale bars: $0.5 \mathrm{~cm}(\mathbf{f}, \mathbf{g}) ; 200 \mu \mathrm{m}(\mathbf{i}, \mathbf{j})$. Graphs show mean \pm s.e.m. neutrophils (displaying an 85\% reduction in MET protein levels compared to WT; Extended Data Fig. 2a) completely lost this response (Fig. 4g, h and Extended Data Fig. 8f). In line with this, TCM (containing $2.6 \pm 0.3 \mathrm{ng} \mathrm{ml}^{-1} \mathrm{HGF}$ ) promoted transendothelial migration of WT neutrophils, but its effect was $43 \%$ lower on Met KO neutrophils (Fig. 4i). Upon HGF neutralization, WT neutrophils responded to TCM only partially, as did Met KO neutrophils (Fig. 4i). Neither HGF nor TCM influenced neutrophil behaviour on non-activated endothelial cells or bare membranes (Extended Data Fig. 8f-h). Hence, HGF-mediated MET activation is required for neutrophil transendothelial migration to the inflammatory site.
Once migrated inside the tumour, N1 or N2 neutrophils can inhibit or favour tumour progression, respectively ${ }^{19}$. Among the N1 and N2 genes, only the expression of the $\mathrm{N} 1$ marker inducible nitric oxide synthase (Nos2, also known as iNos) was lower in Met KO versus WT TANs but similar in macrophages (Fig. 4j and Extended Data Fig. 8i). Compared to $\mathrm{WT} \rightarrow \mathrm{WT}$ mice, tumours harvested from $\mathrm{KO} \rightarrow \mathrm{WT}$ mice displayed reduced nitric oxide (NO) production and 3-nitrotyrosine (3NT) formation, a sign of NO-mediated cell damage (Fig. 4k-n). In vitro, Met $\mathrm{KO}$ TANs had lower cancer-cell-killing capacity than WT TANs; iNOS inhibition by $N^{\mathrm{G}}$-monomethyl-L-arginine (L-NMMA) blunted this difference (Fig. 4o and Extended Data Fig. 8j). 

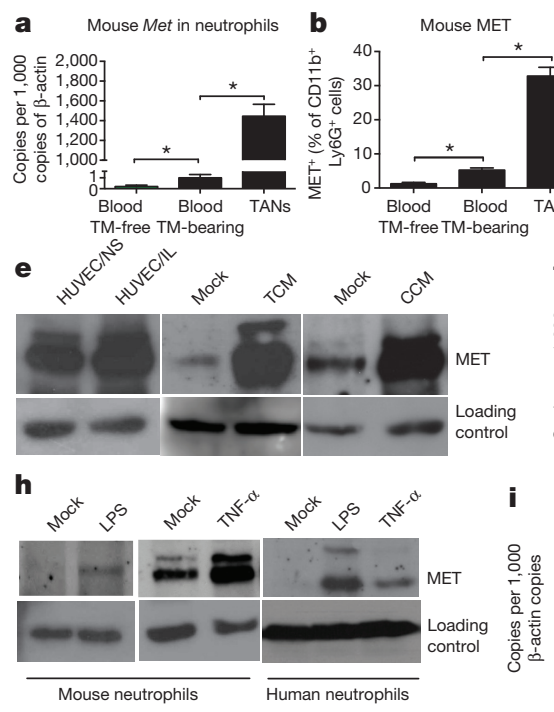
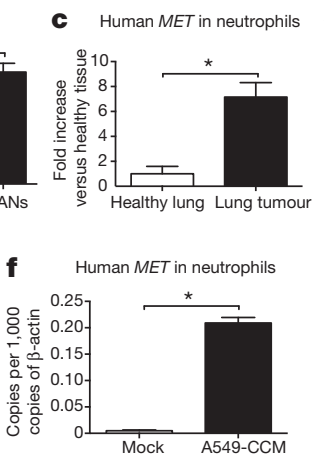

i Mouse Met in neutrophils

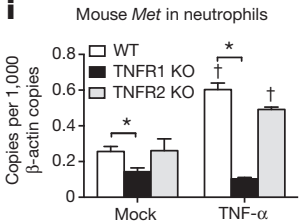

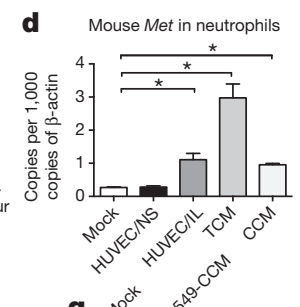

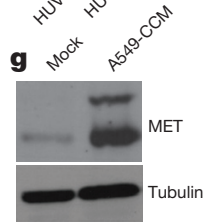

j Mouse Met in neutrophils

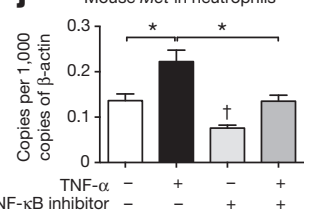

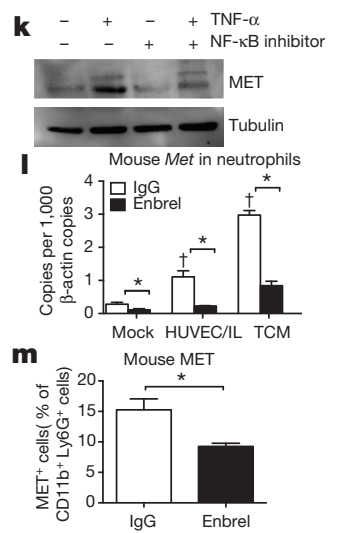

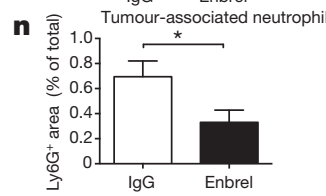

Figure 3 Met expression in neutrophils is induced by tumour-derived soluble factors. a, b, Quantitative polymerase chain reaction with reverse transcription (qRT-PCR) (a) and fluorescence-activated cell sorting (FACS) (b) analysis for MET in blood neutrophils from tumour (TM)-free or LLCtumour-bearing mice and in TANs. c, qRT-PCR for MET in human neutrophils from lung cancer versus healthy tissue. $n=4$ patients. d, e, MET expression by qRT-PCR (d) and western blot (e) in circulating neutrophils from tumour-free mice after co-culture with unstimulated (HUVEC/NS) or IL$1 \alpha$-pre-stimulated (HUVEC/IL) human umbilical vein endothelial cells (HUVECs), or after stimulation with TCM or CCM. f, g, qRT-PCR (f) or western blot (g) for MET in circulating human neutrophils after stimulation with A549-CCM. h, Western blot for MET in mouse and human neutrophils after LPS or TNF- $\alpha$ stimulation. i, qRT-PCR for Met in WT, TNFR1 KO or
TNFR2 KO mouse neutrophils after TNF- $\alpha$ stimulation. $\mathbf{j}, \mathbf{k}$, qRT-PCR (j) and western blot (k) for MET in mouse neutrophils after TNF- $\alpha$ stimulation with or without NF- $\kappa \mathrm{B}$ inhibitor. 1, qRT-PCR for Met in mouse neutrophils cocultured with HUVEC/IL or stimulated with TCM in the presence or absence of Enbrel. $\mathbf{m}, \mathbf{n}$, FACS for MET in TANs ( $\mathbf{m})$ and immunohistochemistry for Ly6G (n) in LLC tumours after Enbrel. Data combine two independent experiments; total mice, 5 per condition. All data in $\mathbf{a}, \mathbf{b}, \mathbf{d}, \mathbf{f}, \mathbf{i}, \mathbf{j}, \mathbf{l}$ are representative of two independent experiments using four biological replicates per condition per experiment. All western blots were repeated three times on independent biological replicates. Full western blot images are shown in Supplementary Fig. 1. Loading control in $\mathbf{e}, \mathbf{h}$ displays tubulin or actin according to Supplementary Fig. $1 .{ }^{*} P<0.05 ; \dagger P<0.05$ versus mock (i, l) or versus untreated (j). Graphs show mean \pm s.e.m.
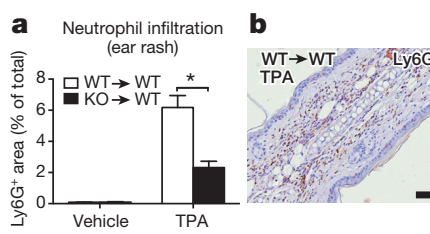

$$
\text { c }
$$

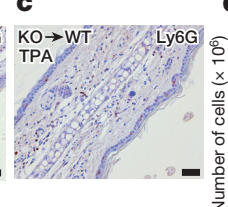
d Neutrophil infiltration

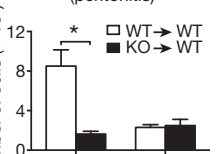
0 Neutrophils Macrophages f Neutrophil infiltration
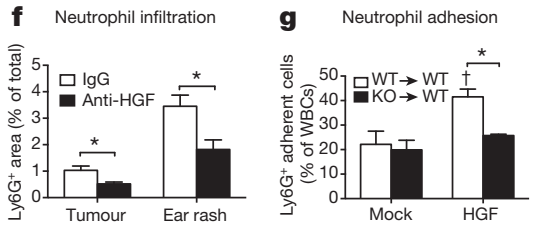

h Neutrophil transmigration

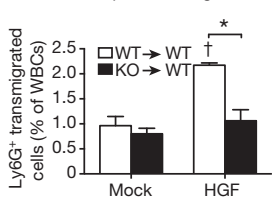

Mock
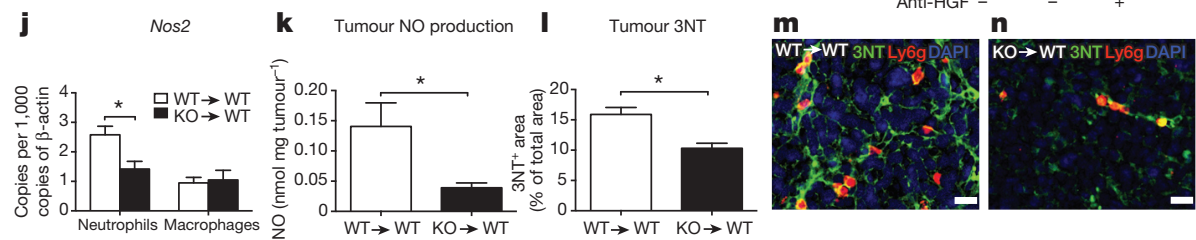

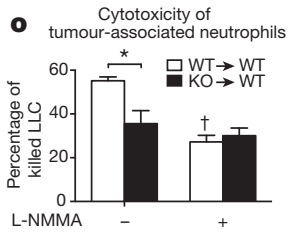

L-NMMA

p
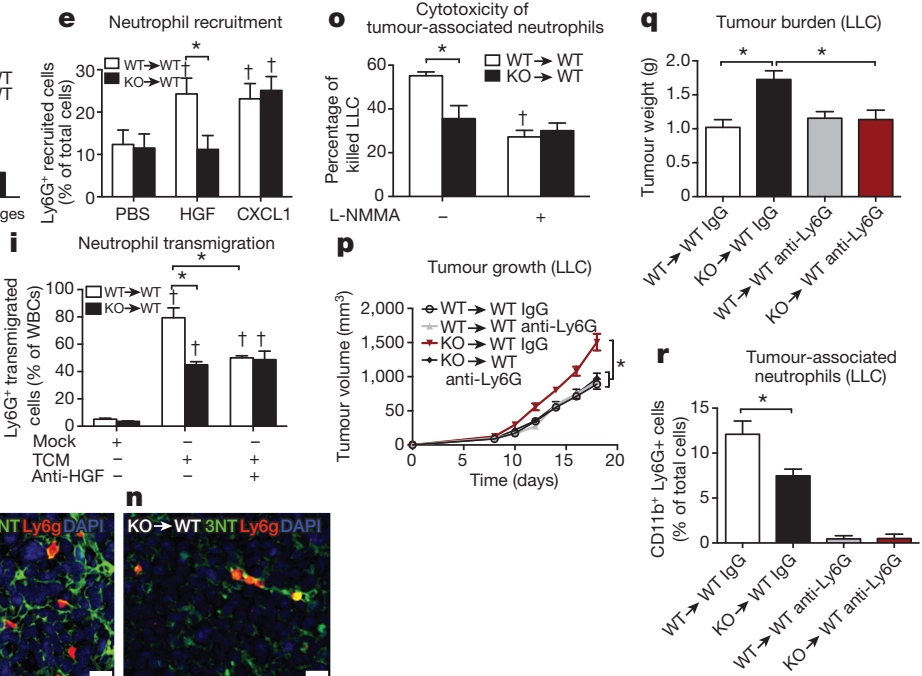

Figure $4 \mid$ MET is required for neutrophil transendothelial migration and cytotoxicity. a-c, Neutrophil quantification (a) on 12-O-

tetradecanoylphorbol-13-acetate (TPA)-painted ear skin (b, c). Data combine two independent experiments; total mice: 10 per condition for vehicle; 14 per condition for TPA. d, FACS analysis for $\mathrm{Ly}_{6 \mathrm{G}}{ }^{+}$neutrophils or F4/80 ${ }^{+}$ macrophages on peritoneal lavages after zymosan-induced peritonitis. Data are representative of two independent experiments using 4 mice per condition per experiment. e, FACS analysis for neutrophil recruitment towards HGF or CXCL1 in air pouch assays. Data combine three independent experiments; total mice: 10 per condition. f, Ly6G infiltration in LLC tumours or in TPA-painted ear skin after anti-HGF. Data combine two independent experiments; total mice: IgG, 11; anti-HGF, 6. g-i, Neutrophil adhesion to HUVEC/IL (g) and transendothelial migration in response to HGF (h) or TCM with or without anti-HGF (i). Data in $\mathbf{g}-\mathbf{i}$ are representative of three independent experiments using three biological replicates per condition per experiment. WBCs, white blood cells. j, k, qRT-PCR for Nos2 in LLC-tumour-associated neutrophils or macrophages (j) and tumour-derived NO production (k). 1-n, Quantification (l) and representative images $(\mathbf{m}, \mathbf{n})$ of $3 \mathrm{NT}$ and Ly6G co-stained LLC tumour sections. DAPI, 4',6-diamidino-2-phenylindole. Data in $\mathbf{j}-\mathbf{n}$ combine two independent experiments; total mice: 8 per condition. o, TAN cytotoxicity against LLC cells with or without L-NMMA. Data are representative of four independent experiments using three biological replicates per condition per experiment. p-r, LLC tumour growth (p), weight (q) and TANs (r) after neutrophil-depleting anti-Ly6G treatment. Data combine two independent experiments; total mice: 16 per condition. ${ }^{*} P<0.05$; $\uparrow P<0.05$ versus $\mathrm{PBS}$ $(\mathbf{e})$, versus mock $(\mathbf{g}-\mathbf{i})$, and versus WT $\rightarrow \mathrm{WT}$ untreated (o). Scale bars: $100 \mu \mathrm{m}$ $(\mathbf{b}, \mathbf{c}) ; 20 \mu \mathrm{m}(\mathbf{m}, \mathbf{n})$. Graphs show mean \pm s.e.m. 
HGF-stimulated WT but not Met KO neutrophils displayed enhanced NO release and cytotoxicity, which was abated by L-NMMA (Extended Data Fig. 8k, 1).

We then hypothesized that HGF/MET pathway is key for antitumoural neutrophils only. Neutrophil depletion in WT $\rightarrow$ WT chimaeras did not affect LLC tumour growth, implying that in this tumour model anti-tumoural and pro-tumoural neutrophils are in balance (Fig. 4p-r). The same treatment in $\mathrm{KO} \rightarrow \mathrm{WT}$ mice reduced tumour growth by $34 \%$ (Fig. 4p-r), indicating that Met deletion inhibits recruitment and activation of cytotoxic, but not of pro-tumoural neutrophils, which are instead blocked by the anti-Ly6G antibody (Fig. 4r and Extended Data Fig. 8m).

In sum, we demonstrate that MET is induced by inflammatory stimuli. This receptor is then required for neutrophil extravasation to inflamed tissues. Extravasated neutrophils respond to HGF by producing cytotoxic nitric oxide (Extended Data Fig. 1). All these steps restrain non-specific immune reactions to the inflammatory site, preventing damage of healthy organs.

These findings highlight a double-edged role of MET in cancer: on the one hand, in MET-addicted tumours, this pathway is vital for the cell cycle and survival ${ }^{2}$; on the other hand, it promotes anti-tumorigenic activities in neutrophils. Thus, alternative approaches targeting MET on cancer cells only, and trials guided by new patient selection strategies will be important to maximize the efficacy of MET inhibition in oncological diseases ${ }^{3,4,20}$.

Finally, given the fact that MET-inhibiting drugs are not associated with overt toxicity ${ }^{1}$, MET-targeted therapies might ameliorate the symptoms of inflammatory disorders in which neutrophils are important for disease pathogenesis ${ }^{21}$.

Online Content Methods, along with any additional Extended Data display items and Source Data, are available in the online version of the paper; references unique to these sections appear only in the online paper.

\section{Received 13 June 2013; accepted 13 March 2015.}

Published online 18 May 2015.

1. Gherardi, E., Birchmeier, W., Birchmeier, C. \& Vande Woude, G. Targeting MET in cancer: rationale and progress. Nature Rev. Cancer 12, 89-103 (2012).

2. Bertotti, A. et al. Only a subset of Met-activated pathways are required to sustain oncogene addiction. Sci. Signal. 2, ra80 (2009).

3. Lennerz, J. K. etal. MET amplification identifies a small and aggressive subgroup of esophagogastric adenocarcinoma with evidence of responsiveness to crizotinib. $J$ Clin. Oncol. 29, 4803-4810 (2011).

4. Choueiri, T.K. et al. Phase ll and biomarker study of the dual MET/VEGFR2 inhibitor foretinib in patients with papillary renal cell carcinoma. J. Clin. Oncol. 31, 181-186 (2013).

5. Comoglio, P. M., Giordano, S. \& Trusolino, L. Drug development of MET inhibitors: targeting oncogene addiction and expedience. Nature Rev. Drug Discov. 7, 504-516 (2008).

6. Bussolino, F. et al. Hepatocyte growth factor is a potent angiogenic factor which stimulates endothelial cell motility and growth. J. Cell Biol. 119, 629-641 (1992).

7. Liu, Y. et al. Hepatocyte growth factor and c-Met expression in pericytes: implications for atherosclerotic plaque development. J. Pathol. 212, 12-19(2007).
8. Chen, Q., DeFrances, M. C. \& Zarnegar, R. Induction of met proto-oncogene (hepatocyte growth factor receptor) expression during human monocytemacrophage differentiation. Cell Growth Differ. 7, 821-832 (1996).

9. Baek, J. H., Birchmeier, C., Zenke, M. \& Hieronymus, T. The HGF receptor/Met tyrosine kinase is a key regulator of dendritic cell migration in skin immunity. J. Immunol. 189, 1699-1707 (2012).

10. Adams, D. H. et al. Hepatocyte growth factor and macrophage inflammatory protein $1 \beta$ : structurally distinct cytokines that induce rapid cytoskeletal changes and subset-preferential migration in T cells. Proc. Natl Acad. Sci. USA 91, 7144-7148 (1994)

11. Tesio, M. et al. Enhanced c-Met activity promotes G-CSF-induced mobilization of hematopoietic progenitor cells via ROS signaling. Blood 117, 419-428 (2011).

12. Takeda, Y. etal. Macrophage skewing by Phd 2 haplodeficiency prevents ischaemia by inducing arteriogenesis. Nature 479, 122-126 (2011).

13. Elliott, E. R. etal. Deletion of Syk in neutrophils prevents immune complex arthritis J. Immunol. 187, 4319-4330 (2011)

14. Kishi, Y. et al. Systemic NK4 gene therapy inhibits tumor growth and metastasis of melanoma and lung carcinoma in syngeneic mouse tumor models. Cancer Sci. 100, 1351-1358 (2009).

15. Pennacchietti, S. et al. Hypoxia promotes invasive growth by transcriptional activation of the met protooncogene. Cancer Cell 3, 347-361 (2003).

16. Moghul, A. et al. Modulation of c-MET proto-oncogene (HGF receptor) mRNA abundance by cytokines and hormones: evidence for rapid decay of the $8 \mathrm{~kb}$ c-MET transcript. Oncogene 9, 2045-2052 (1994)

17. Dai, J. Y., DeFrances, M. C., Zou, C., Johnson, C. J. \& Zarnegar, R. The Met protooncogene is a transcriptional target of $\mathrm{NF \kappa B}$ : implications for cell survival. $J$. Cell. Biochem. 107, 1222-1236 (2009).

18. Suga, H. et al. IFATS collection: fibroblast growth factor-2-induced hepatocyte growth factor secretion by adipose-derived stromal cells inhibits postinjury fibrogenesis through a c-Jun N-terminal kinase-dependent mechanism. Stem Cells 27, 238-249 (2009)

19. Fridlender, Z. G. \& Albelda, S. M. Tumor-associated neutrophils: friend or foe? Carcinogenesis 33, 949-955 (2012).

20. Garber, K. MET inhibitors start on road to recovery. Nature Rev. Drug Discov. 13, 563-565 (2014).

21. Wright, H. L., Moots, R. J., Bucknall, R. C. \& Edwards, S. W. Neutrophil function in inflammation and inflammatory diseases. Rheumatology 49, 1618-1631 (2010).

Supplementary Information is available in the online version of the paper.

Acknowledgements The authors thank: R. Stirparo, M. Mambretti and Y. Jönsson for technical assistance; G. Serini, L. Trusolino and P. Bruhns for comments; and E. Radaelli for valuable advice on histological analyses. V.F. and G.D.C. were supported by grants from the Fonds Wetenschappelijk Onderzoek (FWO), A.C. by the Fondazione Umberto Veronesi. S.W. is supported by a Wellcome Trust Senior Clinical Fellowship Award. M.M. is supported by a European Research Council starting grant.

Author Contributions V.F. performed experimental design, all experiments, data acquisition and interpretation. G.D.C. performed in vitro assays and measured tumou experiments. M.D.M. performed ELISA assays, and designed and performed cloning strategies. J.S. performed all the bone marrow transplantations and in vivo tumour experiments. A.A.R.T. and S.W. performed neutrophil isolations and peritonitis assays. Z.G. provided the Mrp8 promoter. S.C. performed tumour experiments and skin rash assays in vivo. E.W. provided clinical samples. H.P. provided data interpretation on the CRC and HCC models. A.C. performed experimental design, mouse tumour experiments, analysis of histological stainings and FACS, data acquisition and interpretation. M.M. performed experimental design, data analysis, conducted scientific direction and wrote the manuscript.

Author Information Reprints and permissions information is available at www.nature.com/reprints. The authors declare no competing financial interests. Readers are welcome to comment on the online version of the paper. Correspondence and requests for materials should be addressed to M.M. (massimiliano.mazzone@vib-kuleuven.be) or A.C. (andrea.casazza@vib-kuleuven.be). 


\section{METHODS}

Animals. The Met floxed mice, a gift from S. S. Thorgeirsson, were backcrossed in a C57BL/6 background. The Tie2:Cre and MMTV-PyMT transgenic lines were obtained from our mouse facility. The Mrp8:Cre mice were a gift from C. A. Lowell and P. Bruhns s $^{1322-26}$. C57BL/6 mice were purchased from Harlan. TNFR1 KO mice and TNFR2 KO mice were a gift from C. Libert. The Met floxed mice were intercrossed for at least two generations with Tie2:Cre or Mrp8:Cre in order to obtain $M e t^{f l f l}$ Cre-negative (WT) or $M e t^{f l / f l}$ Cre-positive (KO) littermates for the specific promoter. All the experimental procedures were approved by the Institutional Animal Care and Research Advisory Committee of the KU Leuven. In all the experiments, mice were gender and age matched (within an age range between 6 and 10 weeks).

Cell lines. Murine Lewis lung carcinoma cells (LLC), melanoma B16F10, and human non-small-cell lung carcinoma A549 cells were obtained from the American Type Culture Collection (ATCC); the murine pancreatic tumour cell line Panc02 and the murine fibrosarcoma cell line T241 were gifts from U. Cavallaro and L. Claesson-Welsh, respectively. LLC, B16F10, A549 and T241 cells were cultured in DMEM (Gibco) supplemented with $2 \mathrm{mM}$ glutamine, 100 units $\mathrm{ml}^{-1}$ penicillin, $100 \mu \mathrm{g} \mathrm{ml}^{-1}$ streptomycin and containing 10\% FBS (DMEM $10 \%$ FBS). Panc02 cells were cultured in RPMI (Gibco) supplemented with $2 \mathrm{mM}$ glutamine, 100 units $\mathrm{ml}^{-1}$ penicillin, $100 \mu \mathrm{g} \mathrm{ml}^{-1}$ streptomycin and containing $10 \%$ FBS. All these murine tumour cell lines are syngeneic in a C57BL/ 6 background, allowing implantation in Met conditional knockout mice or chimaeras. HUVECs were isolated from human umbilical cords and maintained in M199 (Invitrogen) supplemented with $20 \% \mathrm{FBS}, 2 \mathrm{mM}$ glutamine, 100 units $\mathrm{ml}^{-1}$ penicillin, $100 \mu \mathrm{g} \mathrm{ml}^{-1}$ streptomycin, $0.15 \%$ heparin, $20 \mu \mathrm{g} \mathrm{ml}^{-1}$ ECGS (M199 complete). $0.1 \%$ pork gelatin was used to favour the adhesion of HUVECs to the flask bottom. All cells were maintained in a humidified incubator in 5\% $\mathrm{CO}_{2}$ and $95 \%$ air at $37^{\circ} \mathrm{C}$. Three or four different shRNA lentiviral vectors (Sigma) were used to silence Met in LLC, B16F10 or T241 cells (LLC shMet, B16F10 shMet or T241 shMet; see later), or to silence TNFA in HUVECs (HUVEC shTNFA). Scramble lentiviral vectors were used as control. Transduced cells were selected with $8 \mu \mathrm{g}$ $\mathrm{ml}^{-1}$ puromycin. All cancer cell lines and primary HUVECs underwent mycoplasma testing before their use. Negative mycoplasma contamination status was verified using LookOut Mycoplasma PCR Kit (Sigma) and MycoAlert Mycoplasma Detection Kit plus Assay Control (Lonza). Panc02 and T241 cells were both authenticated by Idexx Bioresearch. All cells were passaged in the laboratory for no longer than 6 months after receipt. Supplementary Table 1 lists the sequences of all the shRNA constructs used in this study.

Bone marrow transplantation and blood cell count. Recipient 6-week-old female mice were lethally irradiated $(9.5 \mathrm{~Gy})$ and then intravenously injected with $10^{7}$ bone marrow cells from WT or KO mice $16 \mathrm{~h}$ later. Experiments were initiated 5 weeks after bone marrow reconstitution. Blood cell count was determined using a haemocytometer on peripheral blood collected by retro-orbital bleeding.

Haematopoietic stem/progenitor cell transduction. For MET overexpression or reconstitution in WT or Met KO neutrophils, respectively, lineage-negative haematopoietic stem/progenitor cells (HSPCs) were enriched with the mouse haematopoietic progenitor enrichment kit (Stem Cell Technologies) and checked for purity by FACS according to the manufacturer's protocol. $1 \times 10^{6} \mathrm{cells}^{-1}$ were pre-stimulated for $5 \mathrm{~h}$ with stem span serum-free medium (Stem Cell Technologies) supplemented with IL-3 $\left(20 \mathrm{ng} \mathrm{ml}^{-1}\right)$, SCF $\left(100 \mathrm{ng} \mathrm{ml}^{-1}\right)$, TPO $\left(100 \mathrm{ng} \mathrm{ml}^{-1}\right)$ and FLT-3L (100 $\mathrm{ng} \mathrm{ml}^{-1}$ ) (Promega), and transduced with $1 \times 10^{8}$ transducing units (TU) $\mathrm{ml}^{-1}$ of a lentiviral vector expressing mouse Met under the promoter of the human gene S100A8 (Mrp8:Met), which has been engineered for neutrophil-specific transcriptional targeting, or an empty vector (Mrp8:Empty) as control. Briefly, the promoter driving Met expression in neutrophils only corresponds to a $3.6 \mathrm{~kb}$ DNA fragment encompassing the natural $5^{\prime}$ and $3^{\prime}$ regulatory regions but deleted of its exon coding sequences. Hence, Met is under the control of the $5^{\prime}$ and $3^{\prime}$ untranslated regions of the human S100A8 gene and other proximal cis regulatory sequences present in the surrogate DNA fragment ${ }^{13,22-26}$. Ten hours after the first viral transduction, cells received a second round of their respective lentiviral vector; $7 \mathrm{~h}$ later $1 \times 10^{6}$ cells were injected via tail vein in lethally irradiated C57BL/6 recipient mice. A fraction of transduced HSPCs were cultured and collected after 9 days to measure the number of integrated vector copies per cell genome (vector copy number (VCN)) by qPCR using custom TaqMan assays specific for HIV gag sequences (Applied Biosystems), as previously described ${ }^{27}$. Standard curves for HIV gag (contained by both Mrp8:Empty and Mrp8:Met lentiviral vectors) were obtained from the corresponding plasmids. Fifty nanograms of genomic DNA from each sample were subjected to qPCR in quadruplicate using an ABI Prism 7500 Fast Real-Time PCR System (Applied Biosystems). VCN was determined comparing the amplification signal on the genomic DNA with the standard curve consisting of serial dilutions over a 6 log range (slope, approximately -3.3 ; intercept, approximately 35 ; efficiency percent- age, approximately 100). Average copies per cell genome were calculated taking into account that one murine diploid genome $=5.92 \mathrm{pg}$. The results of this analysis are shown in Supplementary Table 2.

Tumour models. $2 \times 10^{6}$ LLC or $1 \times 10^{6}$ B16F10 cells were injected subcutaneously while $2 \times 10^{6}$ T241 cells were injected intradermally in a volume of $200 \mu \mathrm{l}$ PBS. Tumour volumes were measured three times a week with a calliper. At end stage, tumours were weighed and collected for histological examination or FACS analysis. MMTV-PyMT ${ }^{+}$spontaneous breast tumours were measured 10 weeks after birth ( 6 weeks after bone marrow transplantation), three times a week, and mice were killed at week 16 . Lung metastases were contrasted by intratracheal injection of a $15 \%$ India ink solution, by H\&E staining on lung paraffin sections, or detected by qRT-PCR for the melanoma-specific gene S100B in the models involving B16F10 cells. For orthotopic pancreatic tumour growth, mice were anaesthetized with isoflurane, the stomach exteriorized via abdominal midline incision, and $1 \times 10^{6}$ Panc02 tumour cells in $30 \mu \mathrm{l}$ PBS were injected into the head of the pancreas using a 29-gauge needle. A successful intrapancreatic injection of tumour cells was identified by the appearance of a fluid bleb without intraperitoneal leakage. Mice displaying peritoneal leakage were immediately killed and excluded from the analysis. At day 12, primary tumours were removed and weighed. Enlarged lymph nodes were counted under a stereoscopic microscope. For the chemically induced colorectal cancer model, body-weight-matched mice received one intraperitoneal injection of $10 \mathrm{mg} \mathrm{kg}^{-1}$ of azoxymethane (AOM) followed by 3 cycles of 7 days of $1.5 \%$ (cycle I) or $1.7 \%$ (cycle II-III) dextran sodium sulphate (DSS) in drinking water, starting from the day of AOM injection ${ }^{28}$. After 160 days, the colon was collected and prepared for histological evaluation with the 'Swiss roll' technique ${ }^{29}$. For the oncogene-driven hepatocellular carcinoma model, mice received a 1:1 molar ratio ( $3 \mu \mathrm{g}$ total DNA) of piggyBac transposons encoding for $c-M y c$ and $H-R a s^{G 12 V}$ oncogenes, driven by the PGK promoter, together with the hyperactive piggyBac transposase-encoding plasmid ${ }^{30}$. DNA solutions containing transposon/transposase plasmids were diluted in $2 \mathrm{ml}$ of Ringer's solution and hydrodynamically delivered in $7 \mathrm{~s}$ through the tail vein. Mice were killed 24 weeks after the hydrodynamic injection.

Lung colonization assay. In the experimental metastasis assays, $0.5 \times 10^{6} \mathrm{~B} 16 \mathrm{~F} 10$ cells were injected in the tail vein and lungs were collected after 12 days. To quantify pulmonary seeding, lungs were homogenized in Trizol (Ambion) and RNA was purified with the RNeasy Mini kit (Ambion) according to manufacturer's instructions. The expression of the melanocyte-specific gene $S 100 B$ was measured as a readout of lung colonization by qRT-PCR following reverse transcription to complementary DNA with the QuantiTect Reverse Transcription kit (Qiagen).

Mice treatments. To induce chronic colitis, mice received 3 cycles of 7 days of $1.5 \%$ (cycle I) or $1.7 \%$ (cycle II-III) DSS in drinking water; 2 weeks after the last DSS cycle, the colon was collected and prepared for histological evaluation as described earlier ${ }^{29}$. For in vivo MET inhibition, B16F10 tumour-bearing mice received $40 \mathrm{mg} \mathrm{kg}^{-1} \mathrm{PF}-04217903$ (AbMole Bioscience) or the corresponding vehicle $(0.5 \%$ methylcellulose in saline) via oral gavage every day once a day starting from day 2 after tumour injection and twice a day from day 11 until the end of the experiment; alternatively mice were treated with $50 \mathrm{mg} \mathrm{kg}^{-1}$ INCB28060 (AbMole Bioscience) or $50 \mathrm{mg} \mathrm{kg}^{-1} \mathrm{JNJ}-38877605$ (Selleckchem). For TNF- $\alpha$ inhibition in vivo, LLC tumour-bearing mice were randomized for comparable tumour volumes at the end stage and intraperitoneally (i.p.) injected with $10 \mathrm{mg} \mathrm{kg}^{-1}$ of Enbrel or human IgG in PBS, 3 and 1 day before tumour collection. For HGF inhibition in vivo, LLC tumour-bearing mice were randomized when average tumour volume was $300 \mathrm{~mm}^{3}$ and i.p. injected with $0.2 \mathrm{mg}$ per mouse of anti-HGF blocking antibody (AF-2207, R\&D ${ }^{18,31}$ ) or goat IgG in PBS. Tumours were collected $20 \mathrm{~h}$ later for histological analysis; 12 -O-tetradecanoylphorbol-13-acetate (TPA) ear painting was done $5 \mathrm{~h}$ after antibodies administration and ears were collected $15 \mathrm{~h}$ later. For neutrophil depletion, mice were treated with $50 \mu \mathrm{g}$ per $20 \mathrm{~g}$ body weight of rat anti-mouse Ly6G antibody (clone 1A8, BioXCell) or rat IgG every second day starting from day 4 after LLC tumour injection and every day from day 12 after tumour injection until the end of the experiment. Efficiency of neutrophil depletion was assessed by FACS in blood and tumours.

TPA model of acute skin inflammation. Phorbol ester TPA was used to induce acute skin inflammation as described previously ${ }^{32}$. Briefly, TPA $(2.5 \mu \mathrm{g}$ in $20 \mu \mathrm{l}$ acetone per mouse) was topically applied on the ear skin of anaesthetized mice. The contralateral ear was painted with acetone alone as vehicle control. Mice were killed after $24 \mathrm{~h}$ and ears were collected in 2\% PFA for histological analysis.

Zymosan-mediated acute peritonitis model. To induce acute peritonitis, zymosan A (Sigma) was prepared at $2 \mathrm{mg} \mathrm{ml}^{-1}$ in sterile PBS. Four hours after i.p. injection of $0.1 \mathrm{mg}$ zymosan A per mouse, inflammatory exudates were harvested by peritoneal lavage with $2 \mathrm{ml}$ PBS. Cells were counted with a Burker chamber and stained for Ly6G (1A8) and F4/80 (BM8) for FACS analysis. 
Air pouch assay. To create subcutaneous air pouches, bone marrow transplanted chimaeric mice or Mrp8;Met $t^{f l / l}$ or Mrp8;Met $t^{w t / w t}$ mice were injected with $3 \mathrm{ml}$ of sterile air by dorsal subcutaneous injection with a butterfly $23 \mathrm{G}$ needle on day 0 and on day 3. On day 6, $200 \mathrm{ng}$ per mouse of murine CXCL1 or HGF dissolved in $0.5 \mathrm{ml}$ PBS-Heparin $\left(15 \mathrm{U} \mathrm{ml}^{-1}\right)$ or PBS-Heparin $\left(15 \mathrm{U} \mathrm{ml}^{-1}\right)$ as control, were injected in the newly formed dorsal camera. After $4 \mathrm{~h}$, inflammatory cells were harvested by washing the pouch with $5 \mathrm{ml}$ of PBS. Cells were stained for Ly6G (1A8), washed and resuspended in PBS $0.1 \%$ BSA with unlabelled counting beads and quantified by FACS.

Mouse white blood cell isolation. Blood was collected from the retro-orbital vein in $10 \%$ heparin. For the isolation of white blood cells (WBCs), the blood was diluted in $1.25 \%$ dextran in saline to allow the sedimentation of red blood cells (RBCs). After $30 \mathrm{~min}$, the erythrocyte-poor upper layer was collected and washed in PBS $0.1 \%$ BSA. The remaining RBCs were lysed in a hypotonic solution of $0.2 \%$ $\mathrm{NaCl}$ for $30 \mathrm{~s}$ and brought in isotonic condition with $1.6 \% \mathrm{NaCl}$ and $0.1 \%$ glucose WBCs were washed in PBS $0.1 \%$ BSA, counted and resuspended accordingly with the experimental setting.

Mouse blood neutrophil isolation. Blood was collected from the retro-orbital vein in $10 \%$ heparin and diluted in an equal volume of PBS $0.5 \%$ BSA. Up to $5 \mathrm{ml}$ of diluted blood was layered on top of a discontinuous gradient of Histopaque 1119 $(4 \mathrm{ml})$ and Histopaque $1077(5 \mathrm{ml})$ from Sigma. The gradient was centrifuged for $30 \mathrm{~min}$ at $700 \mathrm{~g}$ with the brake off. The neutrophil layer between the Histopaque 1077 and 1119 was collected and washed in PBS 0.5\% BSA. RBC lysis was performed as described earlier. Neutrophils were washed in PBS 0.5\% BSA, counted and resuspended according to the experimental condition. Alternatively, blood was sedimented in a saline solution containing $1.25 \%$ dextran and neutrophils were negatively selected with magnetic beads ${ }^{33}$. Neutrophil purity, as assessed by the hemocytometer, was always higher than $93 \%$.

Bone marrow neutrophil and mononuclear cell isolation. To reach reasonable amounts of protein, all the western blot analyses in mice were performed on neutrophils isolated from bone marrows. Mice were killed by cervical dislocation. Femurs and tibias were collected in cold sterile Hank balanced salt solution (HBSS; Invitrogen) and flushed with HBSS $0.25 \%$ BSA. Cells were layered on top of a discontinuous gradient of Percoll $81 \%, 62 \%, 55 \%$, freshly prepared and centrifuged for $30 \mathrm{~min}$ at 2,000 $\mathrm{g}$ with the brake off. Monocytes were collected at the interface between the bone marrow cells and the layer of Percoll 55\%, whereas neutrophils were collected at the interface between Percoll 55\% and 62\%. Cells were washed in HBSS $0.25 \%$ BSA and RBC lysis was performed as described earlier. Neutrophils (or monocytes) were washed again, counted and resuspended according to the experimental setting. Neutrophil (or monocyte) purity, as assessed using a haemocytometer, was higher than $87 \%$.

FACS analysis and flow sorting of blood or tumour-associated cells. Blood was collected in $10 \%$ heparin, incubated for 15 min with Mouse BD Fc Block (2.4G2, BD Pharmingen) 1:100 and stained for $20 \mathrm{~min}$ at room temperature. After RBC lysis, cells were washed and resuspended in FACS buffer (PBS containing 2\% FBS and $2 \mathrm{mM}$ EDTA). Tumours were minced in RPMI medium containing $0.1 \%$ collagenase type I and $0.2 \%$ dispase type I (Gibco) for $30 \mathrm{~min}$ at $37^{\circ} \mathrm{C}$ and passed through a 70 and $40 \mu \mathrm{m}$ cell strainer. After RBC lysis, cells were resuspended in FACS buffer. Lungs were collected after $7 \mathrm{~min}$ of transcardial perfusion with saline and processed as for the tumours. Single-cell suspensions were incubated for 15 min at $4{ }^{\circ} \mathrm{C}$ with Mouse BD Fc Block 1:100 in FACS buffer. The antibodies were added directly in the blocking solution in the appropriate combinations (as indicated in the figure legends). CD45 (30F-11), CD11b (M1/70), Ly6G (1A8), CD45R (RA3-6B2), CD3 (17A2), CD4 (RM4-5), IgE (R35-72), CD49b (DX5), Ly6C (AL-21) (all from BD Pharmingen), F4/80 (BM8), CD115 (AF598), MHCII (M5/114.15-12) (all from eBioscience), were used 1:200 for $2 \times 10^{6}$ in $100 \mu \mathrm{l}$; Siglec-F (E50-2440, BD Pharmingen) was diluted 1:750. In all the stainings 7AAD (BD Pharmingen) was used to gate out dead cells. For intra-tumour proliferation, $1 \mathrm{mg}$ of BrdU was i.p. injected in each mouse $4 \mathrm{~h}$ before tumour collection and cell proliferation was quantified on single-cell suspensions with the FITC BrdU Flow Kit (BD Bioscience) according to the manufacturer's protocol. Tumour apoptosis was assessed by staining single-cell suspensions for the apoptotic marker AnnexinV (1:40, BD Bioscience), excluding 7AAD-positive cells. For TAN apoptosis, tumour single-cell suspensions were gated for CD11b (M1/70) and Ly6G (1A8); AnnexinV and 7ADD were used to distinguish apoptotic or dead neutrophils. In vitro neutrophil apoptosis was performed by seeding neutrophils isolated from tumour-bearing mice at a concentration of $1 \times 10^{6}$ per $\mathrm{ml}$ and stimulating them with or without LPS $\left(1 \mu \mathrm{g} \mathrm{ml}^{-1}\right)$, alone or in combination with HGF (100 ng $\mathrm{ml}^{-1}$ ) for $10 \mathrm{~h}$ at $37^{\circ} \mathrm{C}$. Cells were collected, washed and stained for AnnexinV and 7AAD. The combination of CD11b (M1/70), Ly6G (1A8) and MET (eBioclone 7, eBioscience, 1:50) was used to identify triple-positive MET-expressing neutrophils in blood or 7AAD-negative single-cell suspensions from tumours. Freshly stained samples were analysed by FACS Canto II (BD Bioscience). For tumour-associated neutrophil sorting, the myeloid population was enriched by coating with CD11bconjugated magnetic beads (MACS, Miltenyi Biotec), followed by separation through magnetic columns (MACS, Miltenyi Biotec), staining with Ly6G and sorting with a FACS Aria I (BD Bioscience). Cells were collected in RLT buffer (Qiagen) for RNA extraction or resuspended according to the experimental conditions.

Human neutrophil isolation. Ten millilitres of venous blood from healthy volunteers were collected in citrate-coated tubes and isolated by erythrocyte sedimentation with dextran and purification with a discontinuous plasma-Percoll gradient as already described ${ }^{34}$.

Lung cancer patients. We enrolled four non-small-cell lung carcinoma patients with no previous history of oncological, chronic inflammatory, or autoimmune diseases within 10 years before this study. This patient list includes 2 males (61 and 71 years of age) and 2 females (64 and 68 years of age), of which 3 were smokers (1 T1N0M0 adenocarcinoma, 1 T2N0M0 large-cell carcinoma, 1 T3N0M0 squamous-cell carcinoma) and 1 was a non-smoker (T2N0M0 adenocarcinoma). The protocol was approved by the Ethics Committee of the University Hospitals Gasthuisberg (Leuven), and all subjects consented before study participation.

Flow sorting of neutrophils from lung cancer patients. Lung tumour biopsies or healthy tissues were minced in RPMI medium containing $0.1 \%$ collagenase type $\mathrm{I}$, $0.2 \%$ dispase type I and DNase I $100 \mathrm{U} \mathrm{ml}^{-1}\left(60 \mathrm{~min}\right.$ at $\left.37^{\circ} \mathrm{C}\right)$, passed through a $19 \mathrm{G}$ needle and passed through a 70 and $40 \mu \mathrm{m}$ cell strainer. After RBC lysis, cells were resuspended in FACS buffer (PBS containing 2\% FBS and 2 mM EDTA) and counted. The myeloid population, enriched using CD11b-conjugated magnetic beads (MACS, Miltenyi Biotec) and separated through a magnetic column (MACS, Miltenyi Biotec), was stained with anti-CD66b (G10F5, BD Pharmingen, 1:100) for 20 min at $4{ }^{\circ} \mathrm{C}$ and sorted with FACS Aria I (BD Bioscience). Cells were counted and resuspended in RLT buffer (Qiagen) for RNA extraction.

Endothelial cell isolation. Lungs were collected and a single-cell suspension was obtained as described earlier. Endothelial cells were obtained by performing a negative selection for CD45 (30F-11) and F4/80 (CI:A3-1) followed by a positive selection for CD31 (MEC 13.3) by using magnetic beads (Dynabeads, Invitrogen) according to the manufacturer's protocol.

Peritoneal macrophages. Five millilitres of sterile PBS were injected in the peritoneum of anaesthetized mice and collected after $3 \mathrm{~min}$. Cells were centrifuged, washed and cultured overnight.

TCM and LLC (or A549) CCM preparation. Two grams of end-stage LLC tumour explanted from WT mice were chopped and incubated at $37^{\circ} \mathrm{C}$ in $7 \mathrm{ml}$

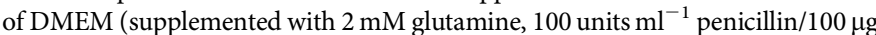
$\mathrm{ml}^{-1}$ streptomycin) FBS-free (DMEM 0\% FBS). $5 \times 10^{4}$ LLC (or A549) were seeded in a 6-multiwell plate in DMEM $10 \%$ FBS and incubated at $37^{\circ} \mathrm{C}$. Medium alone (DMEM 0\% FBS or DMEM 10\% FBS, respectively) was used to prepare mock controls. After $72 \mathrm{~h}$, the medium was filtered, supplemented with $2 \mathrm{mM}$ glutamine and $20 \mathrm{mM}$ HEPES and stored at $-20^{\circ} \mathrm{C}$. TCM and mock medium (DMEM 0\% FBS) were diluted 1:5 in DMEM 10\% FBS; CCM and mock medium (DMEM 10\% FBS) were diluted 4:5 in DMEM FBS-free.

qRT-PCR. For mRNA analysis, $1 \times 10^{5}$ or $3 \times 10^{5}$ mouse or human blood neutrophils, respectively, were incubated in normoxic ( $21 \%$ oxygen) or hypoxic $(1 \%$ oxygen) conditions, or stimulated with TCM (plus $50 \mu \mathrm{g} \mathrm{ml}^{-1}$ Enbrel or human IgG where indicated), CCM, A549-CCM, $100 \mathrm{ng} \mathrm{ml}^{-1}$ of murine or human TNF$\alpha, 50 \mathrm{ng} \mathrm{ml}^{-1} \mathrm{LPS}$, or mock medium in a 96 -multiwell plate for $4 \mathrm{~h}$ at $37^{\circ} \mathrm{C}$. For $\mathrm{NF}-\kappa \mathrm{B}$ inhibition, $0.18 \times 10^{6}$ neutrophils were pre-treated with $10 \mu \mathrm{M} \mathrm{6}$-amino4-(4-phenoxyphenylethylamino) quinazoline (Calbiochem) for $1 \mathrm{~h}$ at $37^{\circ} \mathrm{C}$ and stimulated with $100 \mathrm{ng} \mathrm{ml}^{-1}$ of murine TNF- $\alpha$ for $1 \mathrm{~h}$ at $37^{\circ} \mathrm{C} .2 \times 10^{5}$ HUVECs were seeded in a 24 -multiwell plate coated with $0.1 \%$ gelatin and stimulated with $5 \mathrm{ng} \mathrm{ml}^{-1} \mathrm{IL}-1 \alpha$ in DMEM $10 \%$ FBS for $4 \mathrm{~h}$ at $37^{\circ} \mathrm{C}$. Cells were washed in PBS, collected in RLT buffer (Qiagen) and kept at $-80^{\circ} \mathrm{C}$. RNA was extracted with the RNeasy Micro kit (Qiagen) according to the manufacturer's instructions. Reverse transcription to cDNA was performed with the SuperScript III First Strand cDNA Synthesis Kit (Life Technologies) according to the manufacturer's protocol. Premade assays were purchased from Applied Biosystem, except for Nos2 that was provided by IDT. cDNA, primer/probe mix and TaqMan Fast Universal PCR Master Mix were prepared in a volume of $10 \mu \mathrm{l}$ according to manufacturer's instructions (Applied Biosystems). Samples were loaded into an optical 96-well Fast Thermal Cycling plate (Applied Biosystems) and qRT-PCR were performed using an ABI Prism 7500 Fast Real-Time PCR System (Applied Biosystems)

ELISA. To quantify plasma, intra-tumoural, tumour-released (TCM) and neutrophil-released HGF, a murine HGF ELISA kit (R\&D) was used according to manufacturer's protocols. Blood was collected from tumour-free or tumour-bearing mice and plasma was prepared according to manufacturer's instruction. TCM was prepared as described earlier. Tumour proteins were extracted in Extraction Buffer (20 M Tris $\mathrm{HCl}, 150 \mathrm{mM} \mathrm{NaCl}, 1 \%$ Triton X-100, $10 \%$ glycerol, $5 \mathrm{mM}$ EDTA). $0.2 \times 10^{6}$ neutrophils were cultured for $20 \mathrm{~h}$ in DMEM complete in 
presence or absence of $100 \mathrm{ng} \mathrm{ml}^{-1}$ of murine TNF- $\alpha$. Medium was collected, spun down and supernatant stored at $-80^{\circ} \mathrm{C}$ until use. Mock medium was used as negative control. For phospho-MET quantification, $6 \times 10^{6}$ mouse blood neutrophils isolated from tumour-bearing mice were cultured in the presence or absence of $100 \mathrm{ng} \mathrm{ml}^{-1}$ of murine TNF- $\alpha ; 11 \mathrm{~h}$ later, cells were stimulated or not with $100 \mathrm{ng} \mathrm{ml}^{-1}$ of mouse HGF in the presence of $1 \mathrm{mM}$ orthovanadate for $3 \mathrm{~min}$ at $37^{\circ} \mathrm{C}$, washed in PBS supplemented with $1 \mathrm{mM}$ orthovanadate and $1 \times$ phosStop (Roche) and lysed in Extraction Buffer supplemented with $1 \mathrm{mM}$ orthovanadate, $2 \times$ phosStop and Complete Mini protease inhibitor cocktail (Roche) for $20 \mathrm{~min}$ at $4{ }^{\circ} \mathrm{C}$. After clearance, samples were quantified and the same amount of proteins was used for MET and phospho-MET detection using a sandwich ELISA. Briefly, 96-well microtitre plates (MaxiSorp, Nunc) were coated with $1 \mu \mathrm{g} \mathrm{ml}^{-1}$ of antimouse MET antibody (AF527, R\&D Systems) overnight at $4{ }^{\circ} \mathrm{C}$ and then incubated for $2 \mathrm{~h}$ at room temperature in blocking buffer (PBS, 0.1\% Tween-20, 6\% non-fat dry milk). The same amount of proteins per sample was diluted in blocking buffer and incubated for $2 \mathrm{~h}$ at room temperature on the ELISA plate. After 6 washes in PBS $0.1 \%$ Tween-20, samples were incubated for $2 \mathrm{~h}$ at room temperature with the mouse anti-MET (3D4, Invitrogen) or the mouse anti-phosphotyrosine (4G10, Merck Millipore) antibodies diluted 1:500 in blocking buffer, then washed 6 times in PBS 0.1\% Tween-20, and incubated with goat anti-mouse immunoglobulins conjugated to horseradish peroxidase (sc-2031, Santa Cruz Biotechnology) diluted 1:500 in blocking buffer for $2 \mathrm{~h}$ at room temperature. Signals were developed by $15 \mathrm{~min}$ incubation with the 3,3',5,5' -tetramethylbenzidine (TMB) substrate solution (Promega). After stopping the reaction with $\mathrm{H}_{2} \mathrm{SO}_{4}$, absorbance was measured at $450 \mathrm{~nm}$ and corrected for $630 \mathrm{~nm}$ with a spectrophotometer.

Western blot. To assess MET deletion, bone marrow cells, neutrophils, peritoneal macrophages, monocytes (all cultured overnight in TCM) or endothelial cells were lysed in hot Laemmli buffer $\left(2.5 \%\right.$ SDS, $25 \%$ Tris- $\mathrm{HCl} \mathrm{pH} \mathrm{6.8)} \mathrm{for} 10 \mathrm{~min}$ at $96^{\circ} \mathrm{C}$, sonicated, cleared and quantified. Alternatively, $2 \times 10^{6}$ bone-marrow-derived neutrophils from WT mice were stimulated with TCM, CCM, $100 \mathrm{ng} \mathrm{ml}^{-1}$ of murine TNF- $\alpha$ (or mock medium $0 \%$ FBS or $10 \%$ FBS as control) for $20 \mathrm{~h}$ at $37^{\circ} \mathrm{C}$. For the co-culture with HUVECs, a monolayer of HUVECs was stimulated for $4 \mathrm{~h}$ with $5 \mathrm{ng} \mathrm{ml}^{-1} \mathrm{IL}-1 \alpha$ at $37^{\circ} \mathrm{C}$, and washed before neutrophil seeding. After $20 \mathrm{~h}$ of stimulation, neutrophils were collected using Cell Dissociation Buffer Enzyme Free PBS-Based (Gibco). Cells were washed in PBS, lysed in $15 \mu$ of a protease inhibitor mixture and incubated for $15 \mathrm{~min}$ on ice. The protease inhibitor mixture was obtained by dissolving one tablet of Complete Mini protease inhibitor mixture (Roche) in $5 \mathrm{ml}$ of PBS with $2 \mathrm{mM}$ diisopropyl fluorophosphate (DFP; Acros Organics). After addition of an equal amount of $2 \times$ SDS sample buffer supplemented with $4 \% 2$-mercaptoethanol, the lysates were boiled for $15 \mathrm{~min}$ and kept at $-80^{\circ} \mathrm{C}$ until use. NF- $\mathrm{KB}$ inhibition was achieved by pre-treating $7 \times 10^{6}$ neutrophils with $10 \mu \mathrm{M}$ 6-amino-4-(4-phenoxyphenylethylamino) quinazoline (Calbiochem) for $1 \mathrm{~h}$ at $37^{\circ} \mathrm{C}$; cells were then stimulated with murine TNF- $\alpha$ $\left(100 \mathrm{ng} \mathrm{ml}^{-1}\right)$ for $5 \mathrm{~h}$ before lysis. Human MET was assessed by stimulating $3 \times 10^{7}$ blood neutrophils isolated from the blood of healthy volunteers with A549-CCM, $100 \mathrm{ng} \mathrm{ml}^{-1}$ human TNF- $\alpha, 50 \mathrm{ng} \mathrm{ml}^{-1}$ LPS (or mock medium $10 \%$ FBS as control) for $20 \mathrm{~h}$. Cells were incubated with $2.7 \mathrm{mM}$ DFP for $15 \mathrm{~min}$ at $4{ }^{\circ} \mathrm{C}$, collected and washed in PBS supplemented with $2.7 \mathrm{mM}$ DFP and Complete Mini protease inhibitor $1 \times$, and lysed in hot Laemmli buffer at $96{ }^{\circ} \mathrm{C}$ for $10 \mathrm{~min}$. Cell lysates were sonicated, cleared and quantified. $6 \times$ loading buffer was added before loading on the gel. The following primary antibodies were used: mouse anti-mouse Met (3D4, Invitrogen), mouse anti-mouse $\beta$-actin (I-19, Santa Cruz), mouse anti-vinculin (hVIN-1, Sigma), rabbit anti-human MET (D1C2, Cell Signaling), horseradish peroxidase (HRP)-conjugated anti- $\beta$-tubulin (Abcam). The following secondary antibodies were used: HRP-conjugated goat anti-mouse and HRP-conjugated goat anti-rabbit (Santa Cruz). Signal was visualized by Enhanced Chemiluminescent Reagents (ECL; Invitrogen) or West Femto by Thermo Scientific according to the manufacturer's instructions.

Adhesion assay. $4 \times 10^{4}$ HUVECs were seeded in M199 complete in a 96-multiwell plate, previously coated with $0.1 \%$ gelatin. After $12 \mathrm{~h}$, HUVECs were stimulated with $5 \mathrm{ng} \mathrm{ml}^{-1} \mathrm{IL}-1 \alpha$ in DMEM $10 \%$ FBS at $37^{\circ} \mathrm{C}$. After $4 \mathrm{~h}$ the endothelial monolayer was gently washed and $2.5 \times 10^{5}$ WBCs were isolated indistinctly from Tie2;Met $t^{w t / w t}$ and Tie2;Met $t^{f l / f l}$ mice or from WT $\rightarrow \mathrm{WT}$ and $\mathrm{KO} \rightarrow \mathrm{WT}$ transplanted mice, were seeded on top of it, with or without murine $\operatorname{HGF}\left(50 \mathrm{ng} \mathrm{ml}^{-1}\right)$. After $15 \mathrm{~min}$ non-adherent cells were washed out whereas adherent cells were detached by using a Cell Dissociation Buffer Enzyme Free PBS-Based (Gibco). Cells were stained for Ly6G (clone 1A8), washed and resuspended in PBS-BSA $0.1 \%$ with unlabelled counting beads (BD Bioscience) and quantified by FACS Canto II (BD Bioscience)

Transmigration and migration assay. For the transmigration assay, $2 \times 10^{5}$ HUVECs were seeded on $3 \mu \mathrm{m}$ polycarbonate membrane (Transwell; Costar) previously coated with $0.1 \%$ gelatin in M199 complete. After $12 \mathrm{~h}$, HUVECs were stimulated for $4 \mathrm{~h}$ at $37^{\circ} \mathrm{C}$ in DMEM $10 \%$ FBS with $5 \mathrm{ng} \mathrm{ml}^{-1} \mathrm{IL}-1 \alpha$ and then washed. $5 \times 10^{5}$ WBCs isolated indistinctly from Tie2;Met $t^{t+/ w t}$ and Tie2;Met $t^{f l / f l}$ mice or from $\mathrm{WT} \rightarrow \mathrm{WT}$ and $\mathrm{KO} \rightarrow \mathrm{WT}$ transplanted mice were seeded on top of the endothelial monolayer, while mock medium, TCM (with or without $3 \mu \mathrm{g} \mathrm{ml}^{-1}$ anti-HGF antibody AF-2207; R\&D) $)^{18,31}$ or $50 \mathrm{ng} \mathrm{ml}^{-1}$ murine HGF was added in the bottom. After $2 \mathrm{~h}$ at $37^{\circ} \mathrm{C}$, transmigrated cells were collected from the bottom chambers and from the lower side of the filter with cold PBS 0.5\% EDTA. Cells were stained and $\mathrm{Ly}_{6 \mathrm{G}}{ }^{+}$cells were quantified as described earlier. In the migration assays WBCs were seeded directly on top of $3 \mu \mathrm{m}$ polycarbonate porous membranes.

Nitric oxide measurement by FACS. Neutrophils isolated from the blood of WT or KO LLC-tumour bearing mice were co-cultured for $4 \mathrm{~h}$ with LLC shMet, washed and resuspended in $20 \mathrm{mM}$ HEPES-PBS, and incubated for 10 min with $5 \mu \mathrm{M}$ DAF-FM diacetate (Molecular Probes) in the absence or presence of mouse HGF $\left(100 \mathrm{ng} \mathrm{ml}^{-1}\right)$ at $37^{\circ} \mathrm{C}$. Cells were then washed and analysed by FACS.

Cytotoxicity assay. LLC shMet or T241 shMet were transduced with a luciferaseexpressing lentiviral vector (EX-hLUC-Lv114 from GeneCopoeia); $10^{4}$ cells were then seeded in DMEM 10\% FBS in a 96-multiwell plate. After $4 \mathrm{~h}, 0.2 \times 10^{6}$ neutrophils purified from the blood of tumour-bearing mice or directly from the tumours themselves, were co-cultured with the cancer cells in DMEM 2\% FBS for $4 \mathrm{~h}$ at $37^{\circ} \mathrm{C}$, with or without $100 \mathrm{ng} \mathrm{ml}^{-1}$ mouse HGF or $1 \mathrm{mM} \mathrm{L-NMMA}$ (Sigma). After washing, adherent cells were lysed in $0.2 \%$ Triton, $1 \mathrm{mM}$ dithiothreitol (DTT). Luciferase signal was revealed with a microplate luminometer. The use of shMet was thought to prevent any possible confounding activity of MET on cancer cell survival and thus to restrict the effect of HGF to neutrophils only.

Histology and immunostainings. To obtain serial $7-\mu \mathrm{m}$-thick sections, tissue samples were immediately frozen in OCT compound or fixed in $2 \%$ PFA overnight at $4{ }^{\circ} \mathrm{C}$, dehydrated and embedded in paraffin. Paraffin slides were first rehydrated to proceed further with antigen retrieval in citrate solution (DAKO). Cryosections were thawed in water and fixed in $100 \%$ methanol. If necessary, $0.3 \% \mathrm{H}_{2} \mathrm{O}_{2}$ was added to methanol to block endogenous peroxidases. The sections were blocked with the appropriate serum (DAKO) and incubated overnight with the following antibodies: rat anti-CD45 (30F-11, BD Pharmingen) 1:100, rat anti-Ly6G (1A8, BD Pharmingen) 1:100, rat anti-CD31 (MEC 13.3, BD Pharmingen) 1:200, rabbit anti-FITC (Serotec) 1:200, goat anti-phosphohistone H3 (Cell Signaling) 1:100, rat anti-F4/80 (CI:A3-1, Serotec) 1:100, mouse anti-NK1.1-biotin (PK136, BD Pharmingen) 1:200, rat anti-CD45R (RA3-6B2, BD Pharmingen) 1:100, rat anti-CD4 (H129.9, BD Pharmingen) 1:100, rat anti-CD8 (53-6.72, BioXCell) 1:100, hamster anti-CD11c biotin (N418, eBioscience) 1:100, mouse anti-3-nitrotyrosin (HM.11 Santa Cruz) 1:200. Appropriate secondary antibodies were used: Alexa488-or Alexa568-conjugated secondary antibodies (Molecular Probes) 1:200, HRP-labelled antibodies (DAKO) 1:100, Biotin-labelled antibodies (Jackson ImmunoResearch) 1:100. When necessary, tyramide signalling amplification (Perkin Elmer, Life Sciences) was performed according to the manufacturer's instructions. Whenever sections were stained in fluorescence, ProLong Gold mounting medium with DAPI (Invitrogen) was used. Otherwise, 3,3' -diaminobenzidine was used as a detection method followed by Harris' haematoxilin counterstaining, dehydration and mounting with DPX. Apoptotic cells were detected by the TUNEL method, using the AptoTag peroxidase in situ apoptosis detection kit (Millipore) according to the manufacturer's instructions. For the double staining TUNEL and Ly6G, TUNEL staining was performed as described earlier, followed by Ly6G staining by using the Vectastain ABC kit (Vector Laboratories) according to the manufacturer's instructions. Tumour necrosis and lung metastasis were evaluated by H\&E staining. Necrotic area was defined as the area including necrotic cancer cells, inflammatory cells and stromal cells, compared to the total area of the field. Necrotic cells display a more glassy homogeneous appearance in the cytoplasm with increased eosinophilia, while the nuclear changes are reflected by karyolysis, pyknosis and karyorrhexis. Alternatively, the necrotic tissue was visualized by autofluorescence as previously described ${ }^{35}$. Microscopic analysis was done with an Olympus BX41 microscope and Cell Sense imaging software or a Zeiss Axioplan microscope with KS300 image analysis software. The morphometric analysis was performed by acquiring 4-6 fields per section on five independent sections (at a distance of $40 \mu \mathrm{m}$ in depth during sectioning) from the same biological tissue sample. The values in the graphs represent the average of the means of at least five samples and the standard error indicates the variability among the different samples.

Hypoxia assessment and tumour perfusion. Tumour hypoxia was detected by injection of $60 \mathrm{mg} \mathrm{kg}^{-1}$ pimonidazole into tumour-bearing mice $1 \mathrm{~h}$ before tumour harvesting. To detect the formation of pimonidazole adducts, tumour cryosections were immunostained with Hypoxyprobe-1-Mab1 (Hypoxyprobe kit, Chemicon) following the manufacturer's instructions. Perfused tumour vessels were counted on tumour cryosections from mice injected intravenously with $0.05 \mathrm{mg}$ fluorescein isothiocyanate (FITC)-conjugated lectin (Lycopersicon esculentum; Vector Laboratories). 
Tumour-derived nitric oxide production. LLC tumours were collected 8 days after injection, cut in pieces of about $5 \times 5 \mathrm{~mm}$, weighted and incubated at $37^{\circ} \mathrm{C}$ in a 24 -multiwell plate with $800 \mu \mathrm{l}$ of DMEM. After $24 \mathrm{~h}$, the media was collected, centrifuged to remove cell debris, and NO levels were measured using the Griess reagent system kit (Promega).

Statistics. Data entry and all analyses were performed in a blinded fashion. All statistical analyses were performed using GraphPad Prism software. Statistical significance was calculated by two-tailed unpaired $t$-test on two experimental conditions or two-way analysis of variance (ANOVA) when repeated measures were compared, with $P<0.05$ considered statistically significant. Data were tested for normality using the D'Agostino-Pearson omnibus test (for $n>8$ ) or the Kolmogorov-Smirnov test (for $n \leq 8$ ) and variation within each experimental group was assessed. Detection of mathematical outliers was performed using the Grubbs' test in GraphPad. Sample sizes for all experiments were chosen based on previous experiences. Independent experiments were pooled and analysed together whenever possible as detailed in figure legends. All graphs show mean values \pm s.e.m.

22. Passegué, E., Wagner, E. F. \& Weissman, I. L. JunB deficiency leads to a myeloproliferative disorder arising from hematopoietic stem cells. Cell 119, 431-443 (2004).

23. Van Ziffle, J. A. \& Lowell, C. A. Neutrophil-specific deletion of Syk kinase results in reduced host defense to bacterial infection. Blood 114, 4871-4882 (2009).

24. Abram, C. L., Roberge, G. L., Pao, L. I., Neel, B. G. \& Lowell, C. A. Distinct roles for neutrophils and dendritic cells in inflammation and autoimmunity in motheaten mice. Immunity 38, 489-501 (2013).
25. Albanesi, M. et al. Neutrophils mediate antibody-induced antitumor effects in mice. Blood 122, 3160-3164 (2013).

26. Lagasse, E. \& Clerc, R. G. Cloning and expression of two human genes encoding calcium-binding proteins that are regulated during myeloid differentiation. $\mathrm{Mol}$. Cell. Biol. 8, 2402-2410 (1988).

27. Hamm, A. etal. PHD2 regulates arteriogenic macrophages through TIE2 signalling. EMBO Mol. Med. 5, 843-857 (2013)

28. Neufert, C., Becker, C. \& Neurath, M. F. An inducible mouse model of colon carcinogenesis for the analysis of sporadic and inflammation-driven tumor progression. Nature Protocols 2, 1998-2004 (2007).

29. Moolenbeek, C. \& Ruitenberg, E. J. The "Swiss roll": a simple technique for histological studies of the rodent intestine. Lab. Anim. 15, 57-59 (1981).

30. Chen, X. \& Calvisi, D. F. Hydrodynamic transfection for generation of novel mouse models for liver cancer research. Am. J. Pathol. 184, 912-923 (2014).

31. Schira, J. et al. Significant clinical, neuropathological and behavioural recovery from acute spinal cord trauma by transplantation of a well-defined somatic stem cell from human umbilical cord blood. Brain 135, 431-446 (2012).

32. Cramer, T. et al. HIF-1 $\alpha$ is essential for myeloid cell-mediated inflammation. Cell $112,645-657$ (2003)

33. Cotter, M. J., Norman, K. E., Hellewell, P. G. \& Ridger, V. C. A novel method for isolation of neutrophils from murine blood using negative immunomagnetic separation. Am. J. Pathol. 159, 473-481 (2001).

34. Haslett, C., Guthrie, L. A., Kopaniak, M. M., Johnston, R. B. Jr \& Henson, P. M. Modulation of multiple neutrophil functions by preparative methods or trace concentrations of bacterial lipopolysaccharide. Am. J. Pathol. 119, 101-110 (1985).

35. Shaked, Y. et al. Rapid chemotherapy-induced acute endothelial progenitor cell mobilization: implications for antiangiogenic drugs as chemosensitizing agents. Cancer Cell 14, 263-273 (2008). 


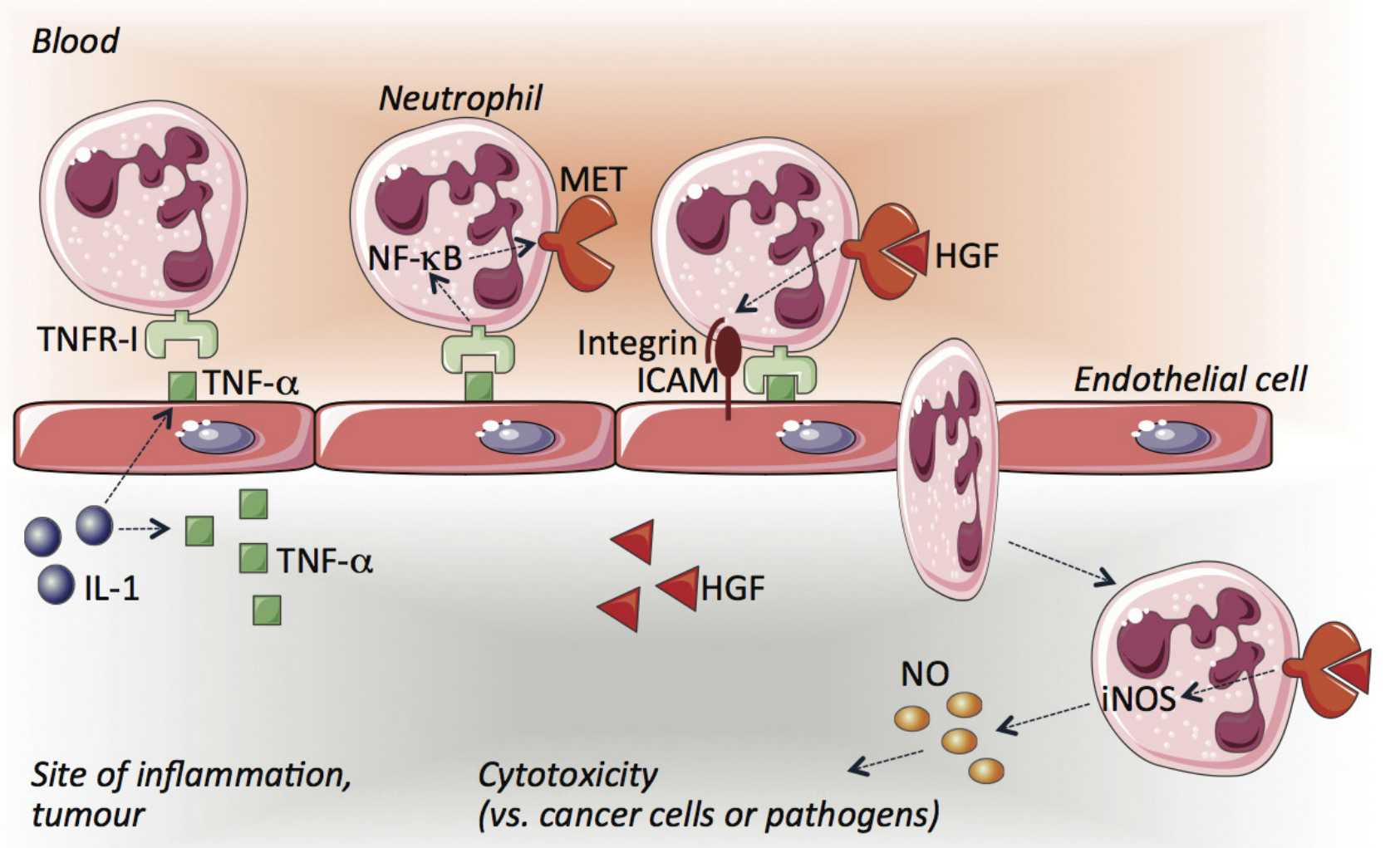

Extended Data Figure $1 \mid$ Scheme illustrating the role of MET in neutrophils. During cancer or infections, the release of cytokines such as IL-1 at the inflammatory site will promote the expression of TNF- $\alpha$ on the endothelium and the surrounding tissue. When circulating neutrophils encounter the activated endothelium, TNF- $\alpha$ will unleash NF- $\kappa B$ through binding to TNFR1, which in turn will induce MET expression on the neutrophil surface. HGF, also released and proteolytically activated at the site of inflammation, will bind to MET and stimulate the firm adhesion of neutrophils to the endothelium, probably via integrin engagement, and thus neutrophil diapedesis. Once extravasated, the HGF/MET pathway will still function on neutrophils by reinforcing their cytotoxic response through the induction of iNOS and NO production, ultimately favouring a bactericidal and tumoricidal neutrophil phenotype. 
BM
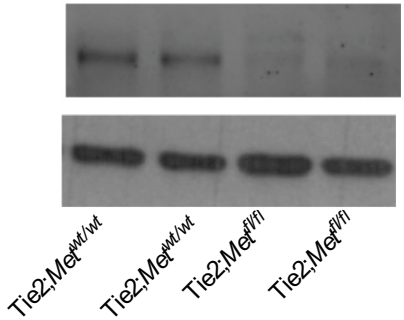

b

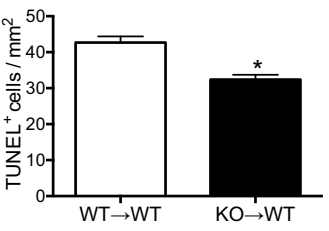

f Tumour necrosis

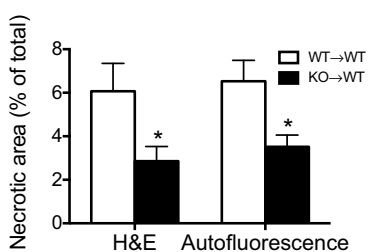

k Tumour proliferation

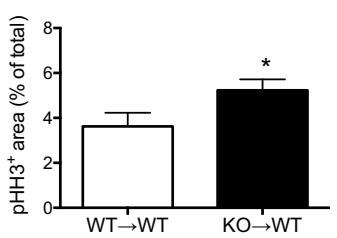

o

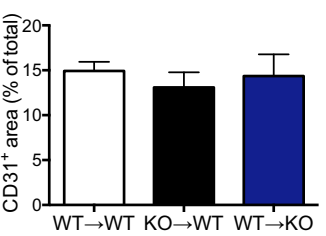

$\mathbf{S}$

Tumour growth

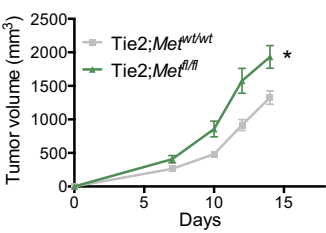

MET

TUBULIN

EC

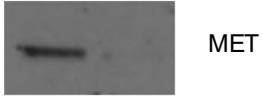

TUBULIN

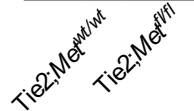

d

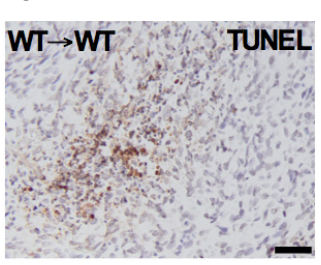

$\mathrm{KO} \rightarrow \mathrm{Wi}$

TUNEL

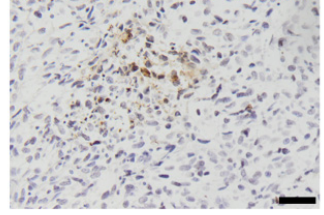

h

i

j
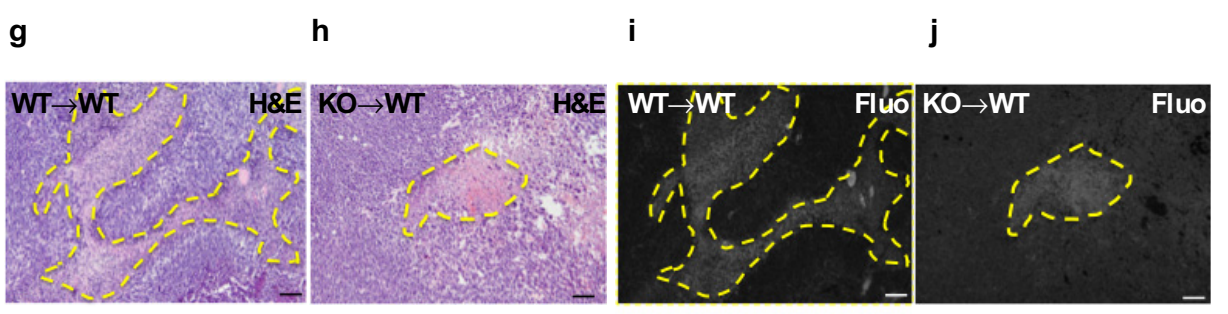

e Tumour apoptosis

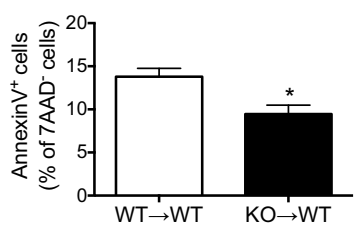

MET

TUBULIN

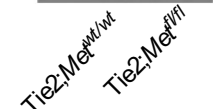

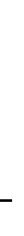

g m

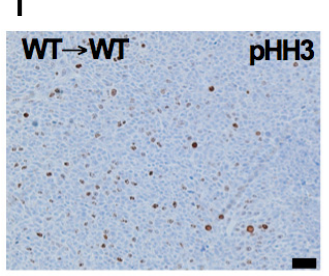

KO $\rightarrow$ WT

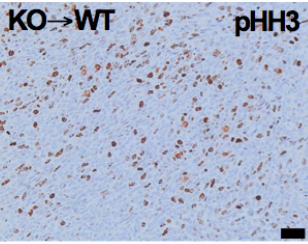

q

Vessel perfusion

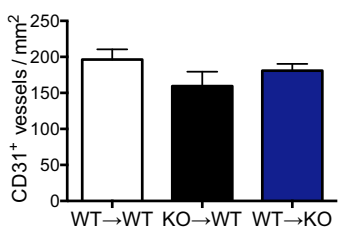

t Tumour burden

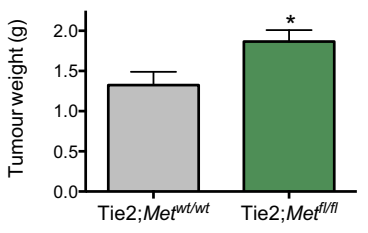

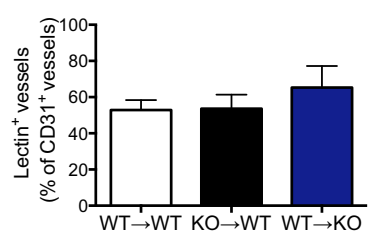

u Lung metastasis

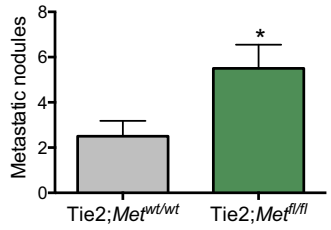

n Tumour proliferation

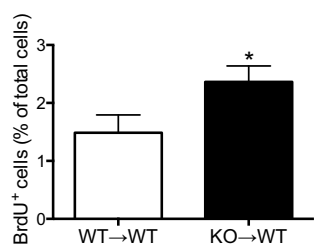

r Tumour hypoxia

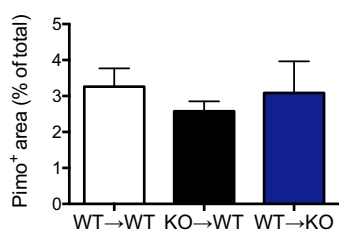

v Tumour growth

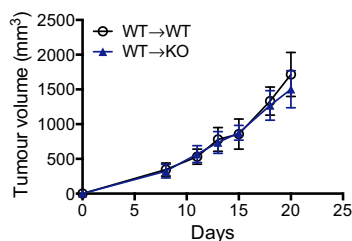


Extended Data Figure $2 \mid$ Met deletion in immune cells, but not in endothelial cells, fosters tumour growth. a, MET expression in total bone marrow (BM) cells, endothelial cells (EC) and neutrophils harvested from Met floxed mice intercrossed with the Tie2:Cre deleter thus generating Tie2; $M e t^{f l / f l}$ $(\mathrm{KO})$ or Tie2;Met ${ }^{w t / w t}(\mathrm{WT})$ mice. Western blots are representative of three repetitions on independent biological replicates. Western blot images have been cropped for presentation. Full scan images are shown in Supplementary Fig. 1. b-d, Quantification (b) and representative images of tumour sections' TdT-mediated dUTP nick end labelling (TUNEL) stainings (c, d) from subcutaneous end-stage LLC tumours in WT $\rightarrow \mathrm{WT}$ and $\mathrm{KO} \rightarrow \mathrm{WT}$ mice. Data combine two independent experiments; total $n=10$ mice per condition. e, FACS quantification of AnnexinV $\mathrm{V}^{+} 7 \mathrm{AAD}^{-}$early apoptotic tumour cells in $\mathrm{WT} \rightarrow \mathrm{WT}$ and $\mathrm{KO} \rightarrow \mathrm{WT}$ mice. Data combine two independent experiments; total $n=8$ mice per condition. $\mathbf{f}-\mathbf{j}$, Tumour necrosis quantification in $\mathrm{WT} \rightarrow \mathrm{WT}$ and $\mathrm{KO} \rightarrow \mathrm{WT}$ mice $(\mathbf{f})$, assessed by histological evaluation of $\mathrm{H} \& \mathrm{E}-$ stained tumour sections $(\mathbf{g}, \mathbf{h})$ and by measurement of autofluorescent tumour areas $(\mathbf{i}, \mathbf{j})$; yellow dotted lines demarcate necrosis. Data combine two independent experiments; total $n=10$ mice per condition.

$\mathbf{k}-\mathbf{m}$, Quantification (k) and representative images of tumour sections stained for the proliferation marker $\mathrm{pHH} 3(\mathbf{l}, \mathbf{m})$ from subcutaneous end-stage LLC tumours in $\mathrm{WT} \rightarrow \mathrm{WT}$ and $\mathrm{KO} \rightarrow \mathrm{WT}$ mice. Data combine two independent experiments; total $n=10$ mice per condition. $\mathbf{n}$, FACS quantification of $\mathrm{BrdU}^{+}$ proliferating tumour cells in $\mathrm{WT} \rightarrow \mathrm{WT}$ and $\mathrm{KO} \rightarrow \mathrm{WT}$ mice. Data combine two independent experiments; total $n=10$ mice per condition. o-r, CD $31^{+}$ vessel area $(\mathbf{o})$, vessel density $(\mathbf{p})$, lectin perfusion $(\mathbf{q})$ and hypoxic $\left(\mathrm{Pimo}^{+}\right)$ area $(\mathbf{r})$ in LLC subcutaneous tumours from $\mathrm{KO} \rightarrow \mathrm{WT}$ mice (in which the haematopoietic/immune system is knocked out for Met) or WT $\rightarrow \mathrm{KO}$ mice (in which endothelial cells only are knocked out for Met) compared to control WT $\rightarrow$ WT mice. Data in o-r combine two independent experiments; total $n: \mathrm{WT} \rightarrow \mathrm{WT}, 12 ; \mathrm{KO} \rightarrow \mathrm{WT}, 8 ; \mathrm{WT} \rightarrow \mathrm{KO}, 8$ $\mathbf{s}-\mathbf{u}$, Subcutaneous LLC tumour growth (s), weight (t) and lung metastases (u) in Tie2;Met $t^{f l f l}$ compared to Tie2;Met $t^{w t / w t}$ mice. Data combine two independent experiments; total $n$ : Tie2; $\mathrm{Met}^{w t / w t}, 12$;

Tie2;Met ${ }^{f l f l}, 10$. v, Subcutaneous LLC tumour growth in endothelial-cell-

specific Met $\mathrm{KO}(\mathrm{WT} \rightarrow \mathrm{KO})$ and control $(\mathrm{WT} \rightarrow \mathrm{WT})$ mice. Data combine two independent experiments; total $n=8$ per condition. $* P<0.05$ versus $\mathrm{WT} \rightarrow \mathrm{WT}(\mathbf{b}, \mathbf{e}, \mathbf{f}, \mathbf{k}, \mathbf{n})$, versus Tie2; $\mathrm{Met}^{w t / w t}(\mathbf{s}-\mathbf{u})$. Scale bars: $50 \mu \mathrm{m}$ $(\mathbf{c}, \mathbf{d}, \mathbf{l}, \mathbf{m}) ; 100 \mu \mathrm{m}(\mathbf{g}-\mathbf{j})$. All graphs show mean \pm s.e.m. 
a

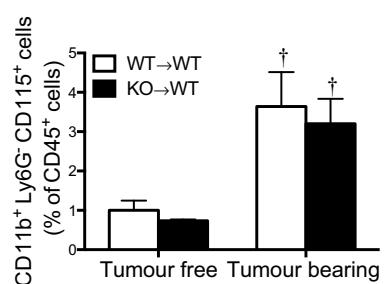

e

Circulating basophils

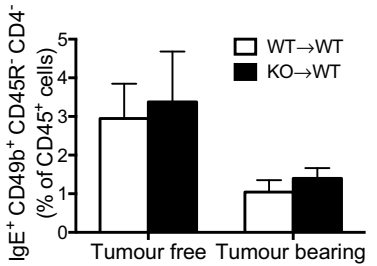

i Tumour-associated neutrophils

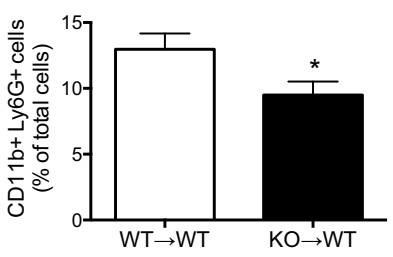

k Tumour-associated neutrophils
Circulating monocytes

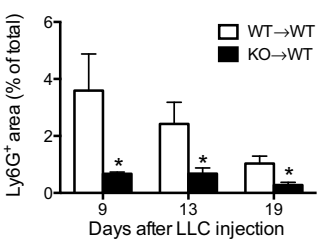

b Circulating lymphocytes

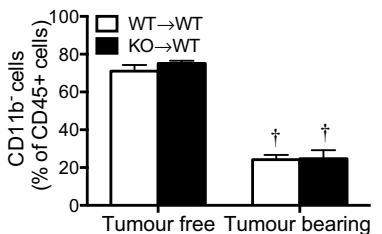

f
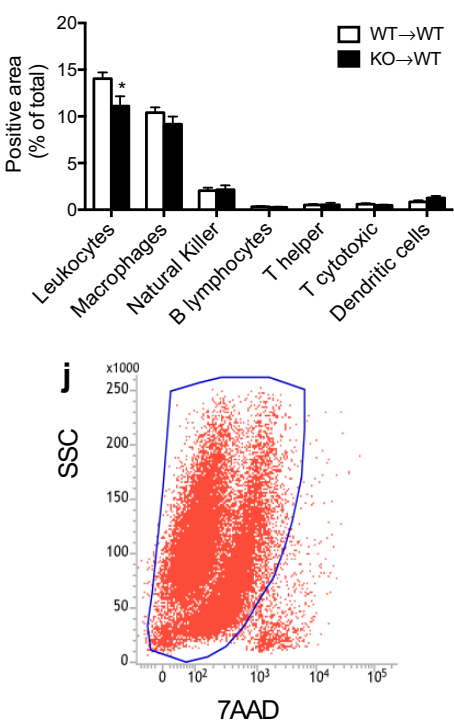

I

Lung-infiltrating

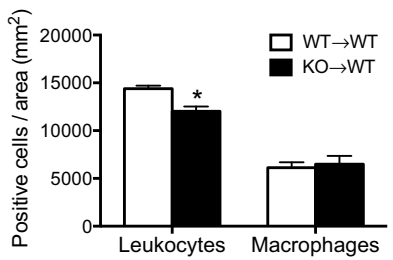

Extended Data Figure $3 \mid$ Circulating and tumour-infiltrating immune cells upon Met deletion. a-e, FACS analysis showing percentages of circulating monocytes (a), lymphocytes (b), neutrophils (c), eosinophils (d) and basophils (e) in tumour-free or in LLC-tumour-bearing WT $\rightarrow$ WT and $\mathrm{KO} \rightarrow \mathrm{WT}$ mice. Data combine two independent experiments; total $n=8$ mice per condition. $\mathbf{f}$, Quantification of LLC tumour sections stained for the pan-leukocyte marker CD45, the macrophage marker F4/80, the NK marker NK1.1, the B lymphocyte marker CD45R, the T helper cell marker CD4, the cytotoxic T cell marker CD8 and the dendritic cell marker CD11c (with exclusion of $\mathrm{F} 4 / 80^{+}$area) in $\mathrm{WT} \rightarrow \mathrm{WT}$ and $\mathrm{KO} \rightarrow \mathrm{WT}$ mice. Data combine two independent experiments; total $n=8$ mice per condition). g, h, FACS quantification for tumour-associated $\mathrm{CD}_{4} 5^{+}$leukocytes $(\mathrm{g})$ or $\mathrm{CD}_{4} 5^{+} \mathrm{IgE}^{+}$

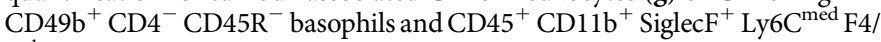
$80^{\text {low }} \mathrm{MHCII}^{-}$eosinophils $(\mathbf{h})$ in $\mathrm{WT} \rightarrow \mathrm{WT}$ and $\mathrm{KO} \rightarrow \mathrm{WT}$ mice. Data combine two independent experiments; total $n=8$ mice per condition. $\mathbf{i}, \mathbf{j}$, FACS quantification (i) and gating strategy (j) for
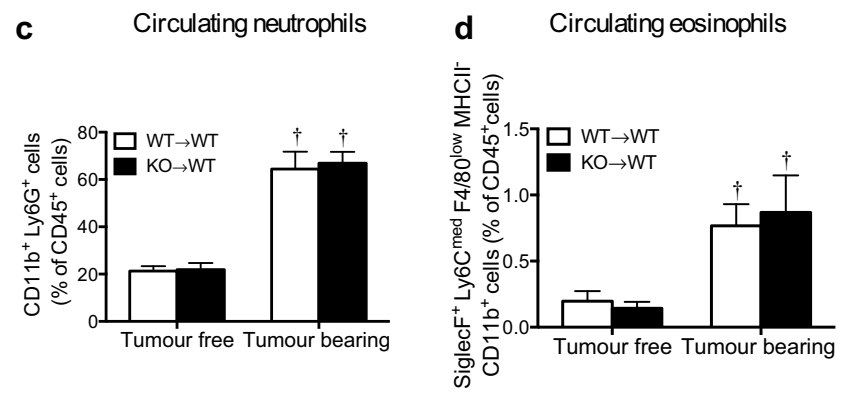

g Tumour-associated leukocytes

\section{h \\ Tumour-associated basophils and eosinophils}
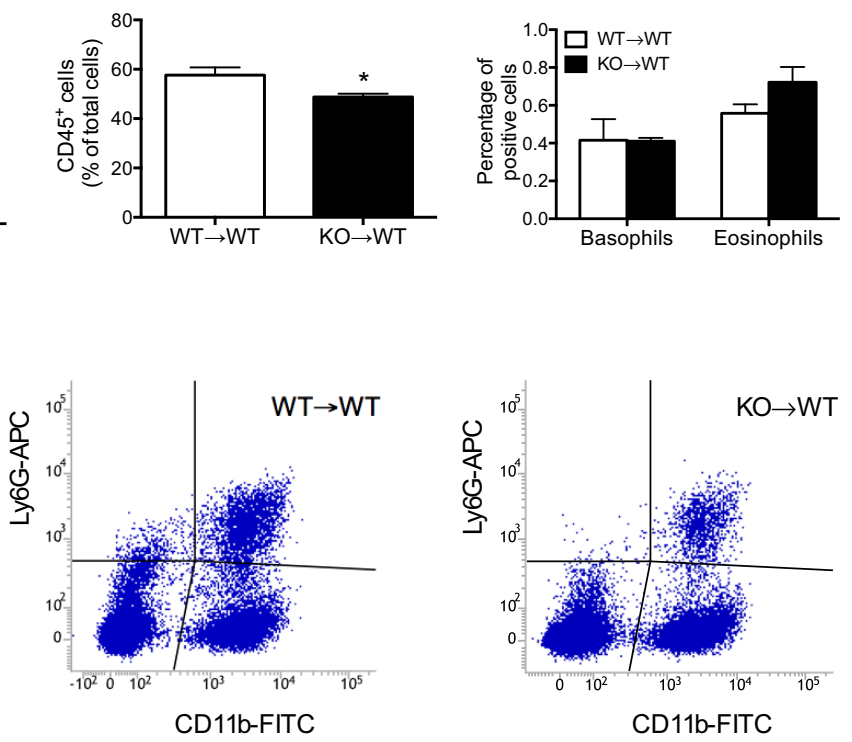

m

Lung-infiltrating

inflammatory cells

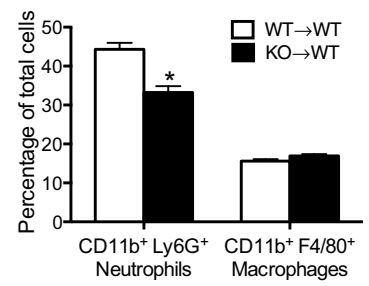

tumour-associated neutrophils selected from the main tumour cell population negative for 7AAD staining; tumour-associated neutrophils were then gated as CD11b and Ly6G double-positive cells. Data combine two independent experiments; total $n: \mathrm{WT} \rightarrow \mathrm{WT}, 11 ; \mathrm{KO} \rightarrow \mathrm{WT}, 10 . \mathbf{k}, \mathrm{Ly} 6 \mathrm{G}^{+}$tumour infiltration at day 9, day 13 and day 19 after LLC subcutaneous tumour injection in $\mathrm{WT} \rightarrow \mathrm{WT}$ and $\mathrm{KO} \rightarrow \mathrm{WT}$ mice. Data combine two independent experiments; total $n=8$ mice per condition. 1, Morphometric quantification of leukocytes and macrophages on CD45- and F480-stained lung sections, respectively, from LLC-tumour-bearing $\mathrm{WT} \rightarrow \mathrm{WT}$ or $\mathrm{KO} \rightarrow \mathrm{WT}$ mice. Data combine two independent experiments; total $n=8$ mice per condition. m, FACS quantification of CD $11 \mathrm{~b}^{+} \mathrm{Ly}_{6 \mathrm{G}}{ }^{+}$neutrophils and $\mathrm{CD} 11 \mathrm{~b}^{+} \mathrm{F} 4 / 80^{+}$ macrophages infiltrating metastatic lungs from LLC-tumour-bearing $\mathrm{WT} \rightarrow \mathrm{WT}$ or $\mathrm{KO} \rightarrow \mathrm{WT}$ mice. Data combine two independent experiments; total $n=8$ mice per condition. ${ }^{*} P<0.05$ versus $\mathrm{WT} \rightarrow \mathrm{WT}$

(f, $\mathbf{g}, \mathbf{i}, \mathbf{k}-\mathbf{m}) ; \dagger P<0.05$ versus tumour free (a-d). All graphs show mean \pm s.e.m. 
a
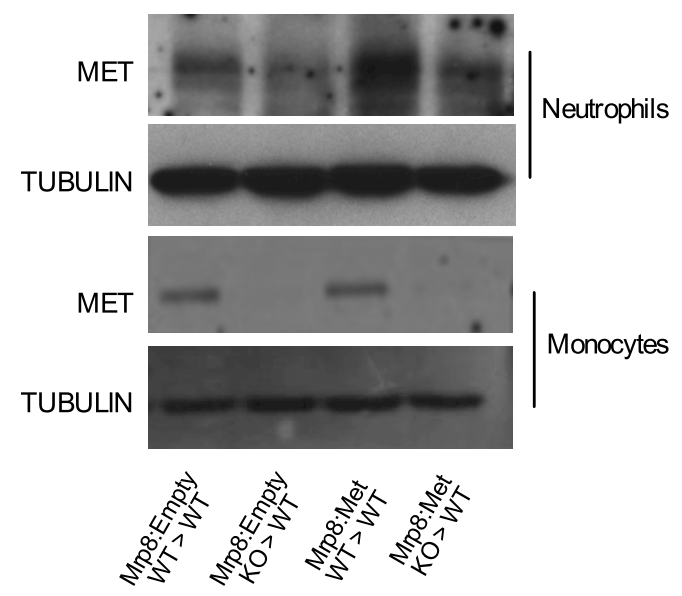

b

Densitometry

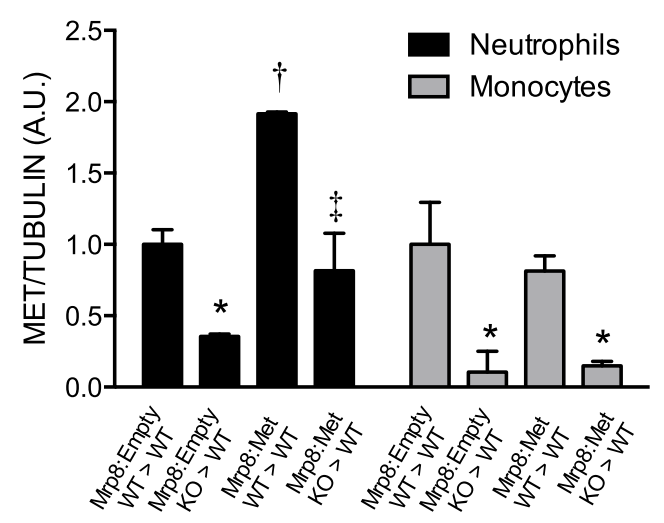

C
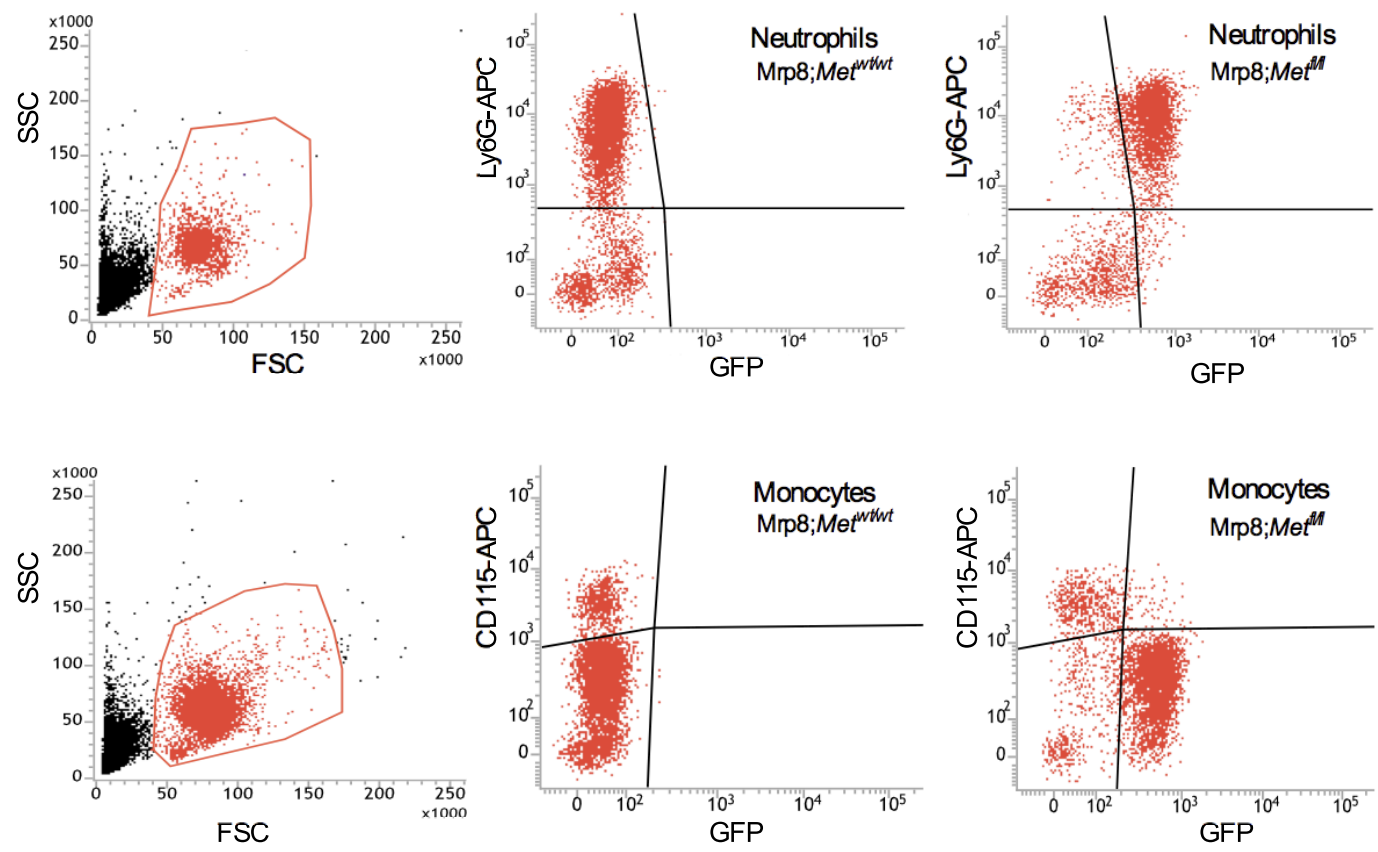

d

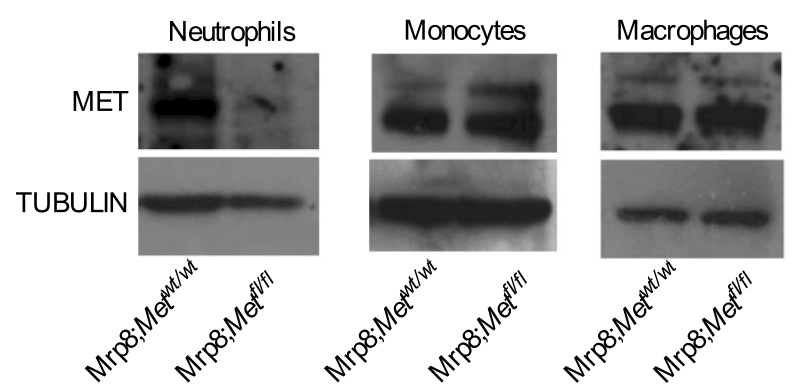

e Tumour-associated neutrophils (LLC)

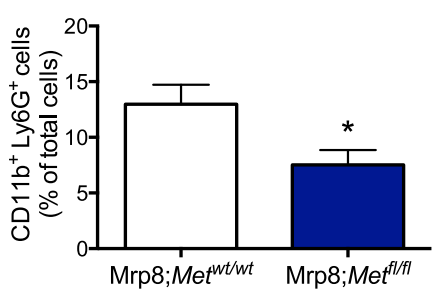


Extended Data Figure $4 \mid$ MET in neutrophils is required for their antitumour activity. a, b, Western blot analysis (a) and relative densitometric analysis (b) for MET expression in bone marrow neutrophils and monocytes upon reconstitution of WT recipient mice by WT or KO HSPCs transduced in vitro with an empty vector (Mrp8:Empty) or a vector expressing Met under the neutrophil-specific promoter Mrp8 (Mrp8:Met); tubulin was used as loading control. Western blots are representative of three repetitions on independent biological samples where each sample is the pool of neutrophils or monocytes isolated from three mice. Densitometric analysis was performed on these three western blots. A.U., arbitrary units. c, FACS analysis for green fluorescent protein (GFP) in circulating $\mathrm{Ly}_{6 \mathrm{G}^{+}}$neutrophils or $\mathrm{CD} 115^{+}$monocytes, harvested from the neutrophil-specific Mrp8:Cre line carrying separate expression of GFP because of an internal ribosome entry site (IRES) downstream the Mrp8-driven cre gene. Data combine two independent experiments; total $n=10$ mice per condition. d, MET expression in neutrophils, monocytes and macrophages harvested from Mrp8;Met $t^{w t / w t}$ or Mrp8;Met $t^{f l f l}$ mice. Western blots are representative of three repetitions on independent biological replicates. e, FACS analysis for $\mathrm{CD}_{11 \mathrm{~b}}{ }^{+} \mathrm{Ly}_{6 \mathrm{G}}{ }^{+}$ neutrophils in subcutaneous LLC tumours from Mrp8; $\mathrm{Met}^{w t / w t}$ or Mrp8;Met $t^{f l f l}$. Data combine two independent experiments; total $n$ : Mrp8;Met ${ }^{w t / w t}, 10 ;$ Mrp8;Met $t^{f l f l}, 11$. Western blot images in a, $\mathbf{d}$ have been cropped for presentation. Full scan images are shown in Supplementary Fig. 1. ${ }^{*} P<0.05$ versus Mrp8:Empty WT $\rightarrow \mathrm{WT}(\mathbf{b})$, versus Mrp8;Met ${ }^{\text {wt/wt }}$

(e); $\dagger P<0.05$ versus Mrp8:Empty WT $\rightarrow \mathrm{WT} ; \ddagger P<0.05$ versus Mrp8:Empty $\mathrm{KO} \rightarrow \mathrm{WT}$. All graphs show mean \pm s.e.m. 


\section{RESEARCH LETTER}

a

Tumour burden (B16F10)
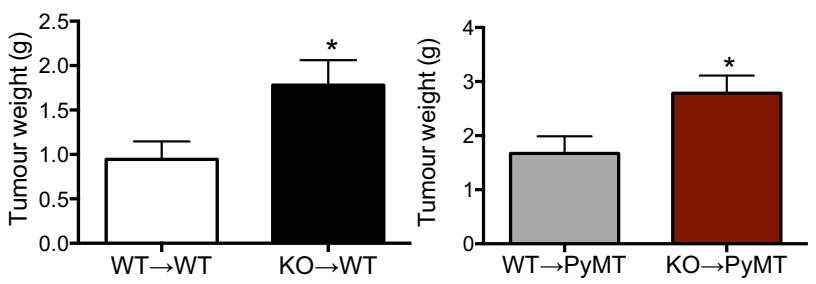

e Tumour-associated neutrophils (PyMT)

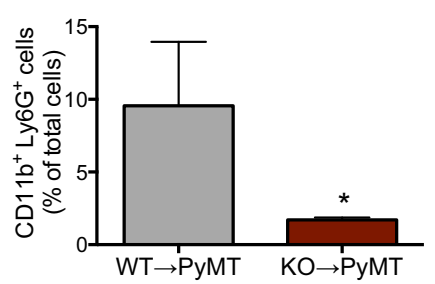

i
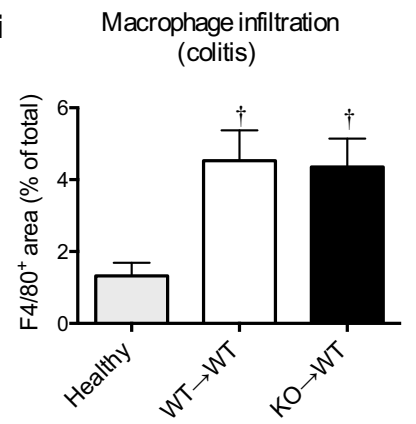

m
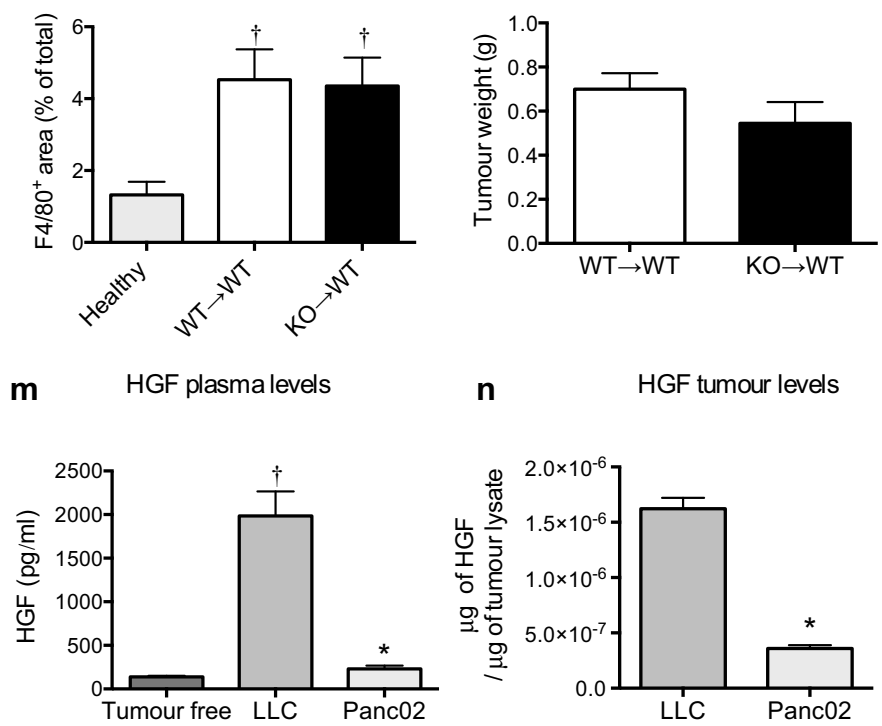

n

HGF tumour levels

o

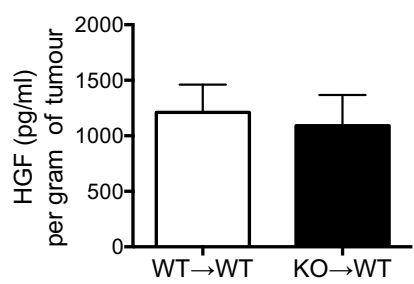

p
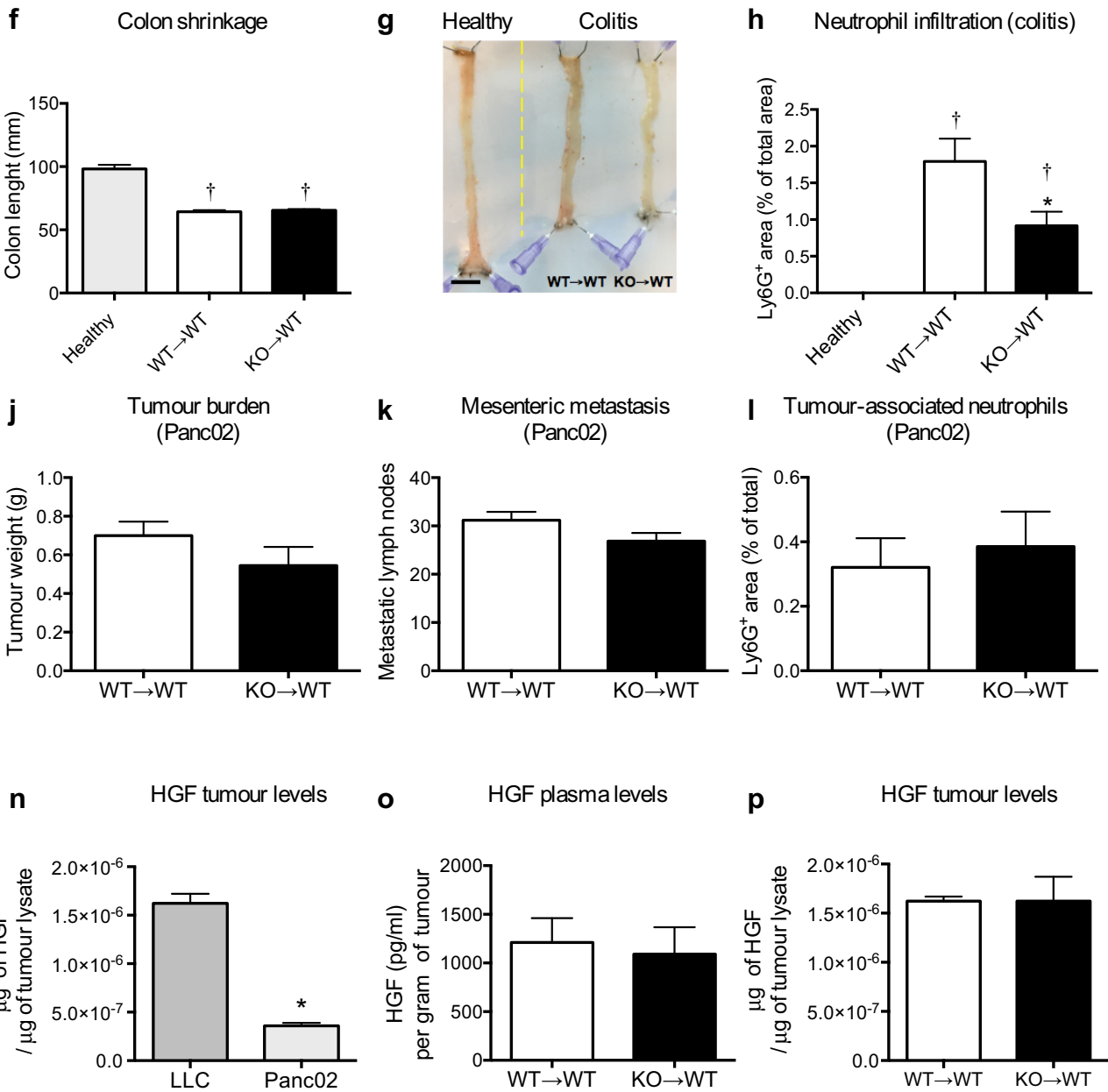

h Neutrophil infiltration (colitis)

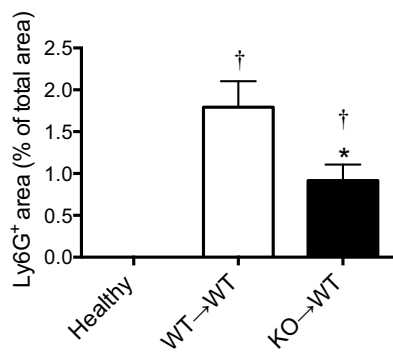

I Tumour-associated neutrophils (Panc02)
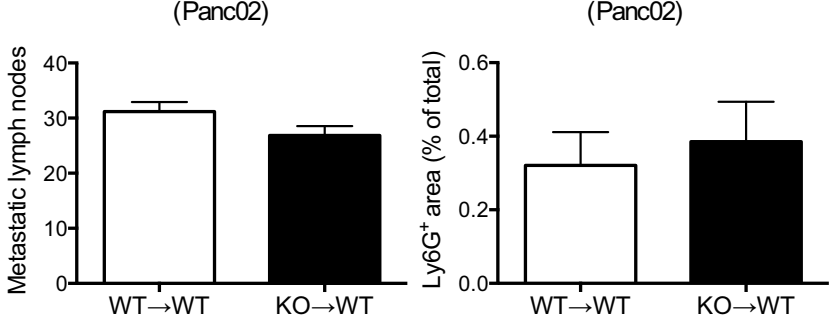

sociated

(T241)

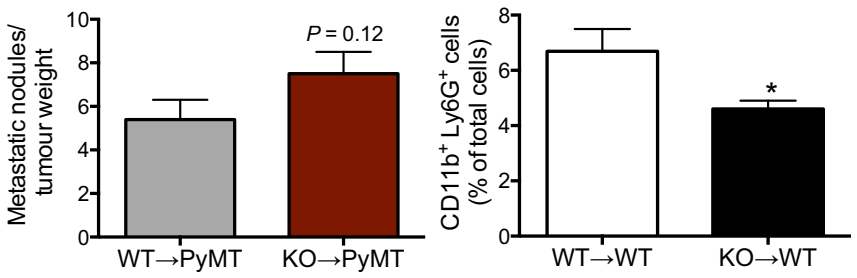

q Tumour-associated neutrophils (B16F10)
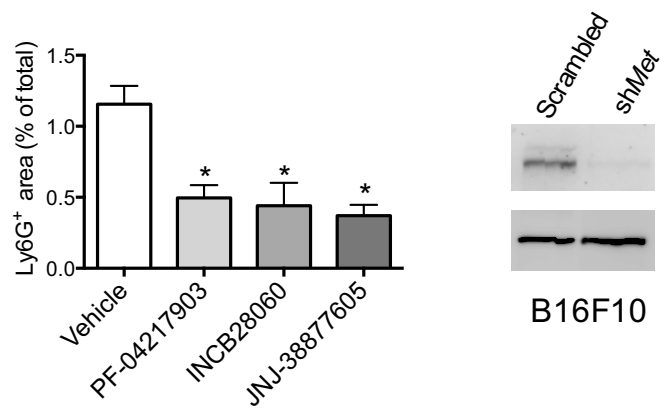

MET

VINCULIN

B16F10 
Extended Data Figure $5 \mid$ Pharmacological and genetic inhibition of MET prevents the recruitment of anti-tumoural neutrophils to several neoplastic tissues and inflammatory sites. a, Tumour weight of subcutaneous B16F10 melanomas in $\mathrm{WT} \rightarrow \mathrm{WT}$ and $\mathrm{KO} \rightarrow \mathrm{WT}$ mice. Data combine two independent experiments; total $n: \mathrm{WT} \rightarrow \mathrm{WT}, 8 ; \mathrm{KO} \rightarrow \mathrm{WT}, 9 . \mathbf{b}, \mathbf{c}$, Total tumour weight (b) and metastatic index (c) in MMTV-PyMT mice reconstituted with WT or Met $\mathrm{KO}$ bone marrow cells before tumour appearance $(\mathrm{WT} \rightarrow \mathrm{PyMT}$ and $\mathrm{KO} \rightarrow$ PyMT mice, respectively). Data combine three independent experiments; total $n: \mathrm{WT} \rightarrow$ PyMT, 13; KO $\rightarrow$ PyMT, 16. d, e, FACS quantification for $\mathrm{CD}_{11 b^{+}} \mathrm{Ly}_{6 \mathrm{G}^{+}}$neutrophils in T241 tumours harvested from WT $\rightarrow \mathrm{WT}$ or $\mathrm{KO} \rightarrow \mathrm{WT}$ mice $(\mathbf{d})$ or in in breast tumours spontaneously grown in $\mathrm{WT} \rightarrow \mathrm{PyMT}$ and $\mathrm{KO} \rightarrow \mathrm{PyMT}$ mice (e). Data combine two independent experiments; total $n=10$ mice per condition (d) or total $n=8$ mice per condition (e). $\mathbf{f}-\mathbf{i}$, Length measurement $(\mathbf{f})$ and representative image (g) of the colon, as well as quantification of neutrophils $(\mathbf{h})$ and macrophages (i) on bowel sections, from $\mathrm{WT} \rightarrow \mathrm{WT}$ and $\mathrm{KO} \rightarrow \mathrm{WT}$ mice upon induction of chronic colitis compared to healthy control. Data combine two independent experiments; total $n$ : healthy, 5 ; WT $\rightarrow \mathrm{WT}, 12 ; \mathrm{KO} \rightarrow \mathrm{WT}, 15$. $\mathbf{j}$, $\mathbf{k}$, Tumour weight $(\mathbf{j})$ and metastatic mesenteric lymph nodes (k) 12 days after orthotopic injection of pancreatic $\mathrm{Panc} 02$ cancer cells in WT $\rightarrow \mathrm{WT}$ and $\mathrm{KO} \rightarrow \mathrm{WT}$ mice. Data combine two independent experiments; total $n=12$ per condition. 1, Histological quantification of $\mathrm{Ly}_{6 \mathrm{G}}{ }^{+}$infiltrates in Panc02 pancreatic tumours harvested from $\mathrm{WT} \rightarrow \mathrm{WT}$ and $\mathrm{KO} \rightarrow \mathrm{WT}$ mice. Data combine two independent experiments; total $n=12$ mice per condition. $\mathbf{m}$, Quantification of plasma HGF in tumour (TM)-free mice, in subcutaneous LLC or orthotopic Panc02 tumourbearing mice. Data combine two independent experiments; total $n$ : tumour free, 10; LLC, 10; Panc02, 8 biological replicates. $\mathbf{n}$, Quantification of HGF in subcutaneous LLC or orthotopic Panc02 tumours. Data combine two independent experiments; total $n$ : LLC, 10; Panc02, 8 biological replicates. $\mathbf{o}, \mathbf{p}$, Quantification of HGF in plasma (o) or in subcutaneous LLC tumours (p) from tumour-bearing $\mathrm{WT} \rightarrow \mathrm{WT}$ and $\mathrm{KO} \rightarrow \mathrm{WT}$ mice. Data are representative of two independent experiments using 5 mice per condition per experiment. q, Quantification of $\mathrm{Ly}_{6} \mathrm{G}^{+}$area on sections from B16F10 melanomas grown in C57BL/6 WT mice, daily treated with PF-04217903, INCB28060, JNJ-38877605, or vehicle as control. Data combine two independent experiments; total $n$ : vehicle, 14; PF-04217903, 9; INCB28060, 6 ; JNJ-38877605, 4. r, Western blot analysis for MET in B16F10 melanoma cells after transduction with a lentiviral vector encoding scrambled or mouse shMet under a constitutive promoter; vinculin was used as loading control. Western blot is representative of three independent repetitions. Western blot images have been cropped for presentation. Full scan images are shown in Supplementary Fig. $1 .{ }^{*} P<0.05$ versus WT $\rightarrow \mathrm{WT}(\mathbf{a}, \mathbf{d}, \mathbf{h})$, versus WT $\rightarrow$ PyMT (b, e), versus LLC (m, n), versus vehicle $(\mathbf{q}) ; \uparrow P<0.05$ versus healthy $(\mathbf{f}, \mathbf{h}, \mathbf{i})$, versus tumour free $(\mathbf{m})$. Scale bar: $10 \mathrm{~mm}(\mathbf{g})$. All graphs show mean \pm s.e.m. 
a

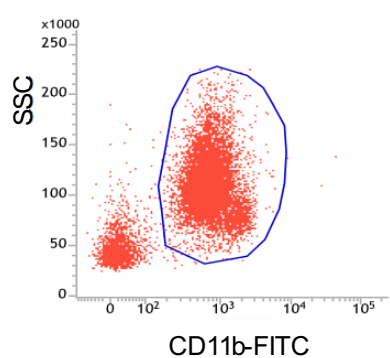

b

Mouse Met in neutrophils

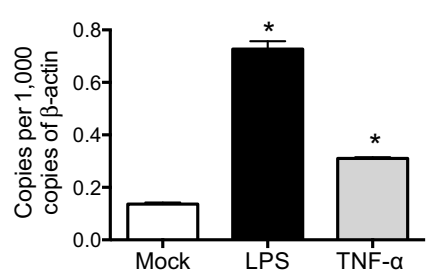

e

Human MET in neutrophils

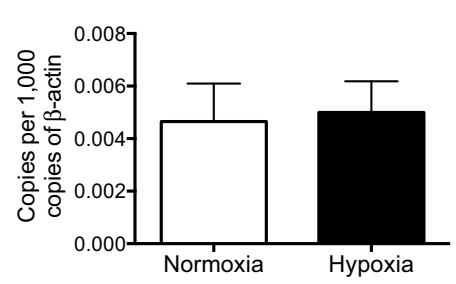

h

Neutrophil HGF

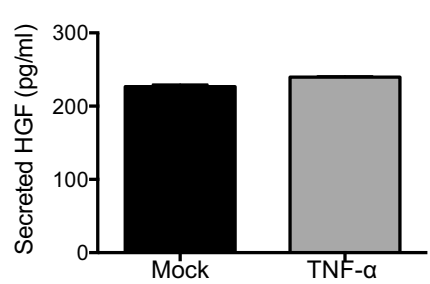

k

Mouse Met in neutrophils

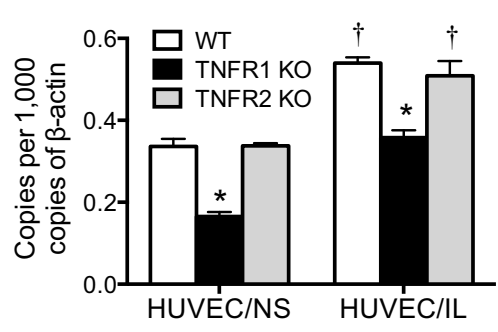

C Human $M E T$ in neutrophils

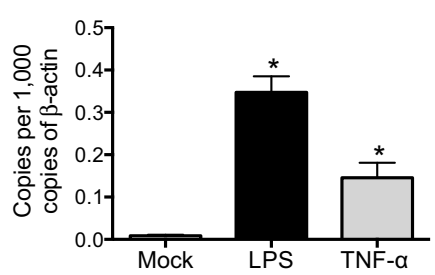

f

MET (ELISA)

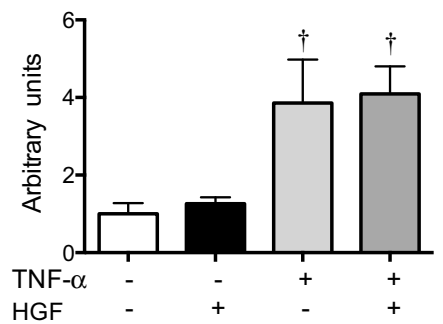

i Human TNFA in endothelial cells

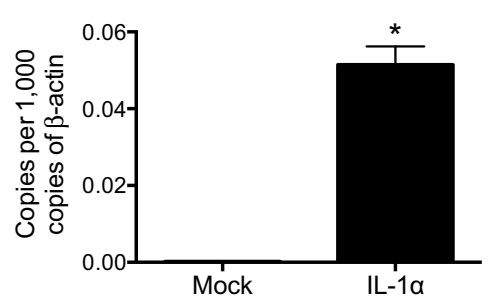

I

Mouse Met in neutrophils

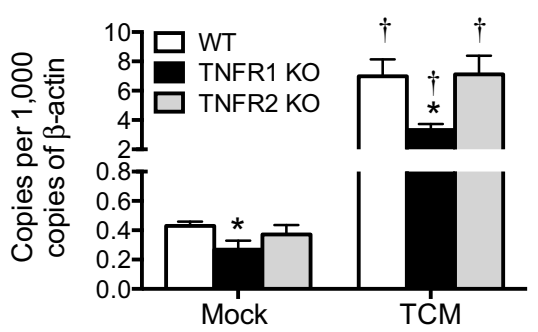

TANs

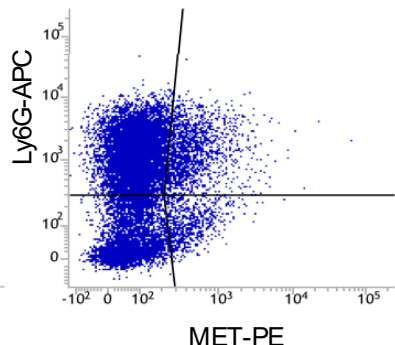

d

Mouse Met in neutrophils

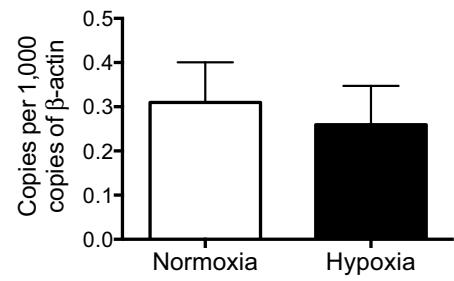

g

Phospho-MET (ELISA)

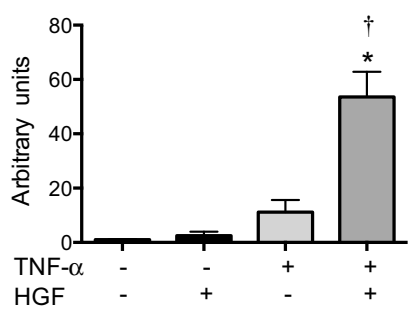

Mouse Met in neutrophils

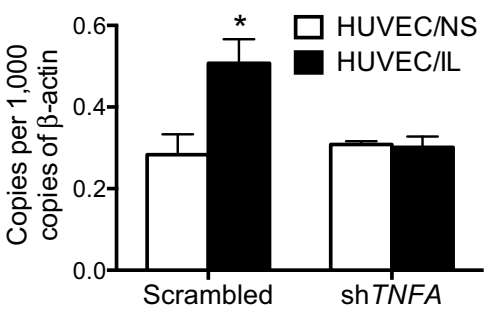

m

Human MET in neutrophils

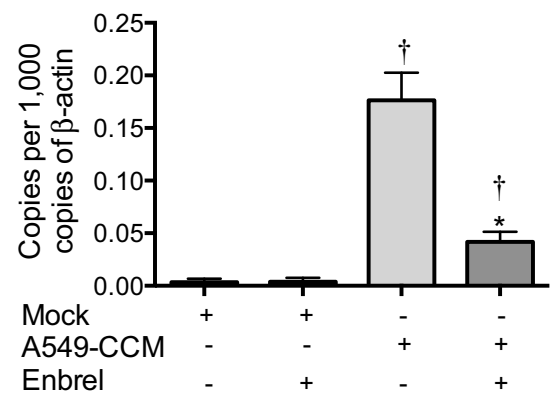


Extended Data Figure $6 \mid$ HGF is required for MET activation upon induction by TNF- $\alpha$. a, Gating strategy related to Fig. 3b to quantify MET expression in blood neutrophils from LLC-tumour (TM)-bearing mice and in TANs, where live cells were first gated as CD11b-positive cells; this population was finally gated for Ly6G and MET to identify MET-expressing Ly6G ${ }^{+}$ neutrophils. b, c, qRT-PCR for MET in mouse (b) and human (c) neutrophils after LPS or TNF- $\alpha$ stimulation. Data are representative of three independent experiments using four biological replicates per condition per experiment. d, e, qRT-PCR for MET expression in mouse (d) or human (e) neutrophils cultured in normoxia $\left(21 \% \mathrm{O}_{2}\right)$ or hypoxia $\left(1 \% \mathrm{O}_{2}\right)$. Data combine two independent experiments; total $n=8$ biological replicates per condition. f, g, ELISA for total MET (f) and phospho-MET (g) from mouse neutrophils stimulated for $3 \mathrm{~min}$ with mock medium or HGF after an overnight incubation with or without TNF- $\alpha$. Data combine three independent experiments; total $n=6$ biological replicates per condition. h. HGF release by neutrophils stimulated with mock medium or TNF- $\alpha$ after $20 \mathrm{~h}$ in culture. Data combine two independent experiments; total $n=6$ biological replicates per condition. i, qRT-PCR for TNFA in HUVECs upon stimulation with IL-1 $\alpha$ compared to mock medium. Data combine two independent experiments; total $n=4$ biological replicates per condition. j, qRT-PCR for Met in mouse neutrophils co-cultured with HUVEC/NS or HUVEC/IL transduced with shTNFA or scramble as control. Data are representative of three independent experiments in which three different shRNA sequences were used; total $n=4$ biological replicates per condition per experiment. k, l, qRT-PCR for Met in WT, TNFR1 KO or TNRF2 KO neutrophils upon co-culture with HUVEC/NS or HUVEC/ IL (k), or after stimulation with conditioned medium (TCM) from LLC tumours (l). Data are representative of two independent experiments using four biological replicates per condition per experiment. $\mathbf{m}$, qRT-PCR for MET in human neutrophils stimulated with A549-CCM in the presence or absence of Enbrel or human IgG as control. Data are representative of two independent experiments using four biological replicates per condition per experiment. ${ }^{*} P<0.05$ versus mock $(\mathbf{b}, \mathbf{c}, \mathbf{i})$, versus TNF- $\alpha$ alone $(\mathbf{g})$, versus HUVEC/NS $(\mathbf{j})$, versus WT $(\mathbf{k}, \mathbf{l})$, versus A549-CCM (m); $\dagger P<0.05$ versus untreated or HGF alone (f, $\mathbf{g})$, versus HUVEC/NS (k), versus mock $(\mathbf{l}, \mathbf{m})$. Graph shows mean \pm s.e.m. 


\section{RESEARCH LETTER}

a

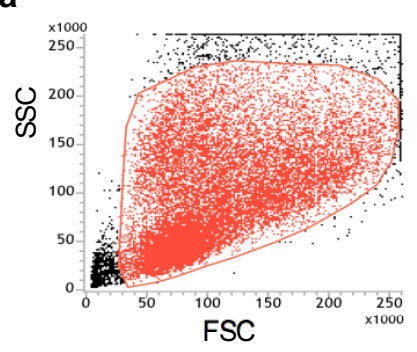

b

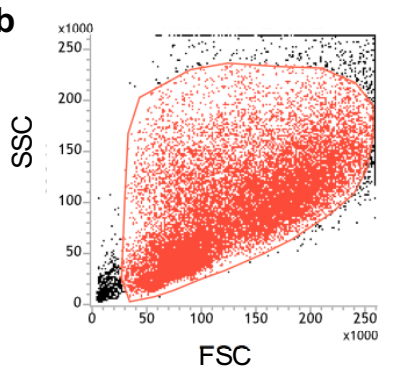

C Intratumoural neutrophil

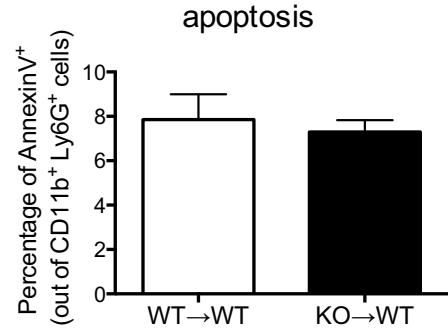

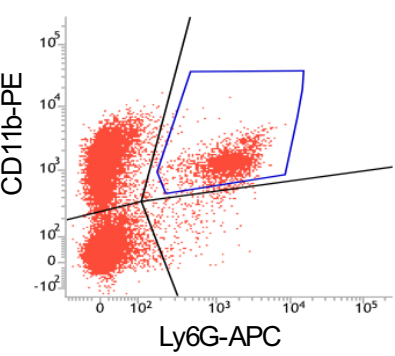

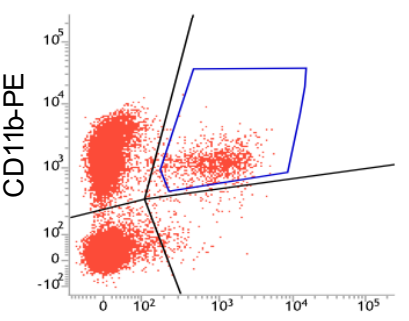

Ly6G-APC

d Intratumoural neutrophil apoptosis

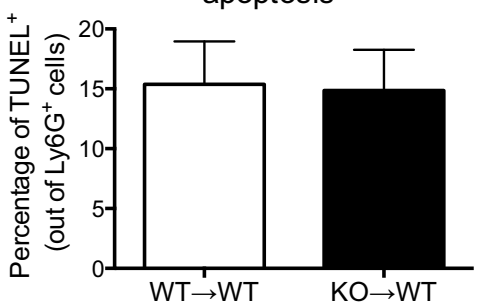

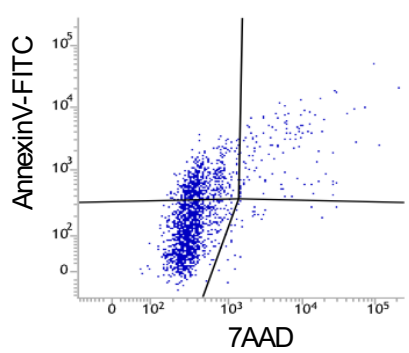

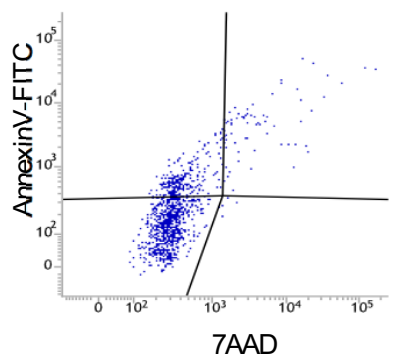

e

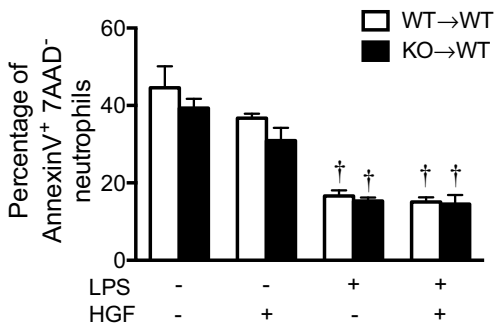

Extended Data Figure $7 \mid$ Met deletion in neutrophils does not affect apoptosis. a, b, Gating strategy of apoptotic WT (a) and Met KO

(b) neutrophils in LLC tumours where single-cell suspensions were first gated for physical parameters and then for CD11b and Ly6G to identify neutrophils as double-positive cells; this population was finally gated for AnnexinV and 7AAD: AnnexinV $\mathrm{V}^{+} 7 \mathrm{AAD}^{-}$cells display early apoptotic neutrophils whereas Annexin $\mathrm{V}^{+} 7 \mathrm{AAD}^{+}$cells display late apoptotic neutrophils. c, Quantification of apoptotic WT and Met KO tumour-associated neutrophils measured by
FACS. Data combine two independent experiments; total $n=7$ mice per condition. d, Quantification of apoptotic WT and Met KO neutrophils on LLC tumour sections by immunohistochemistry. Data combine two independent experiments; total $n: \mathrm{WT} \rightarrow \mathrm{WT}, 7 ; \mathrm{KO} \rightarrow \mathrm{WT}, 6$. e, FACS analysis for AnnexinV and 7AAD of WT or KO neutrophils incubated for $10 \mathrm{~h}$ in the presence or absence of LPS and HGF, alone or in combination. Data combine two independent experiments; total $n=6$ biological replicates per condition. $\dagger P<0.05$ versus untreated or HGF alone. Graph shows mean \pm s.e.m. 
a Neutrophil infiltration (ear rash)

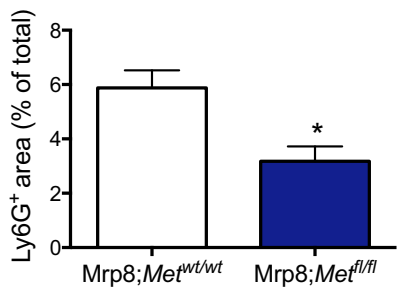

d Lymphocyte infiltration (ear rash)

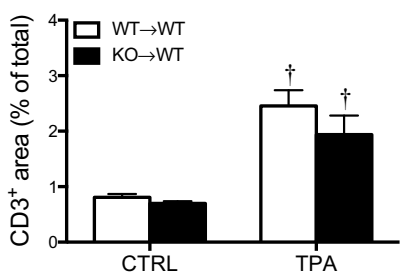

g Neutrophil migration

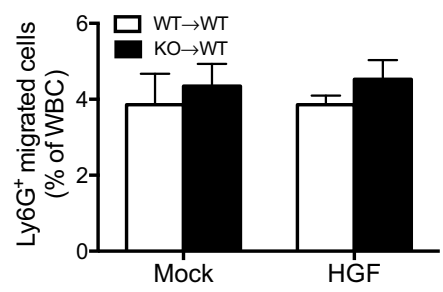

j Cytotoxicity of tumour-associated neutrophils
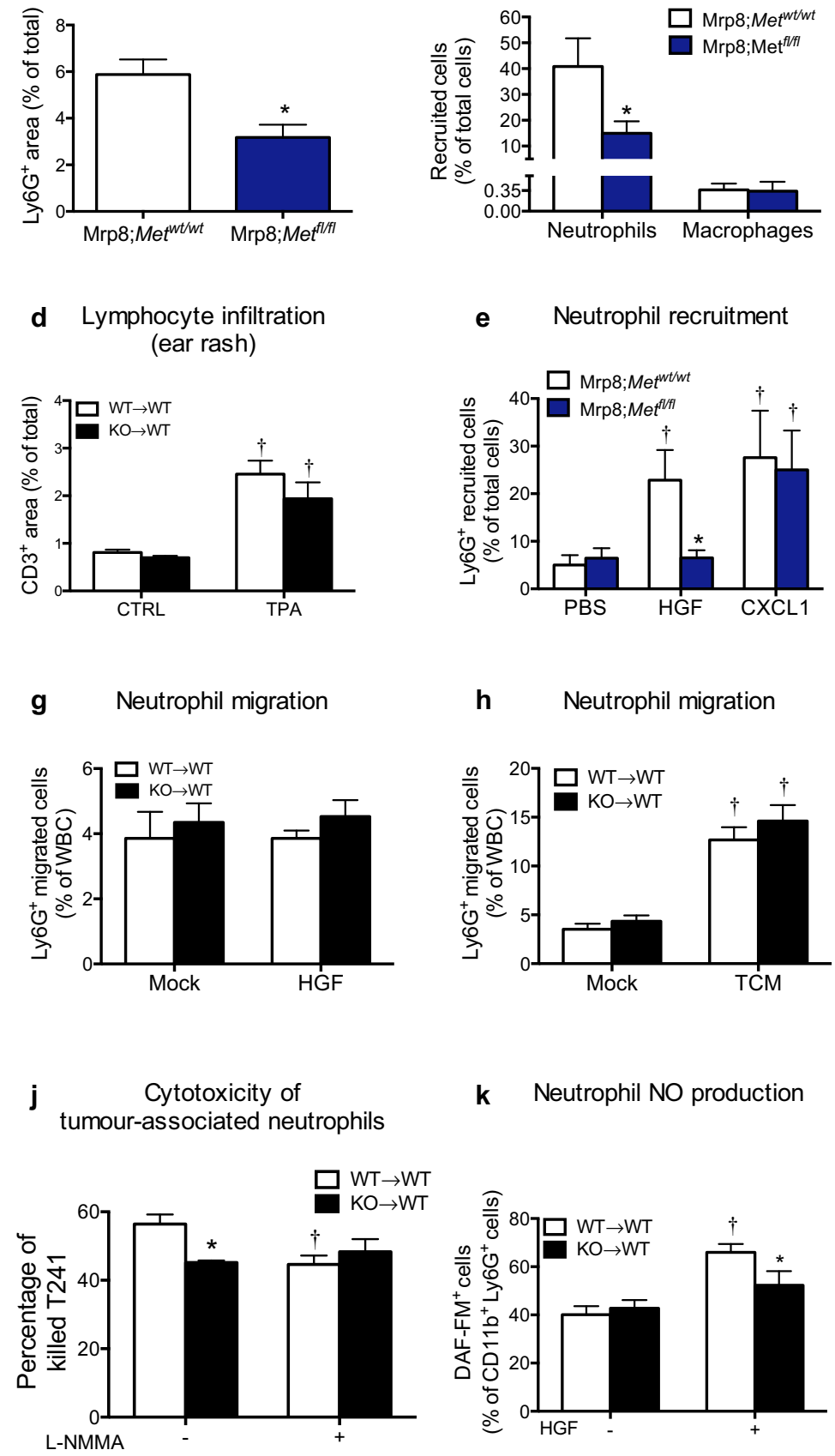

e Neutrophil recruitment

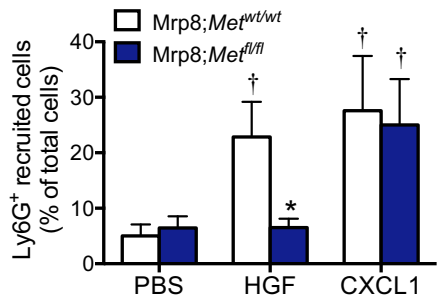

h Neutrophil migration

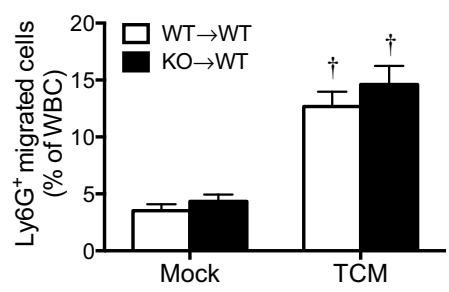

k Neutrophil NO production c

Macrophage infiltration (ear rash)

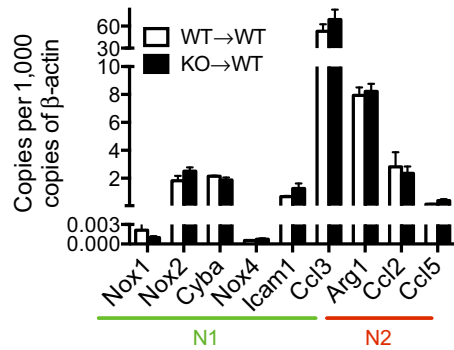

I

Cytotoxicity of circulating neutrophils

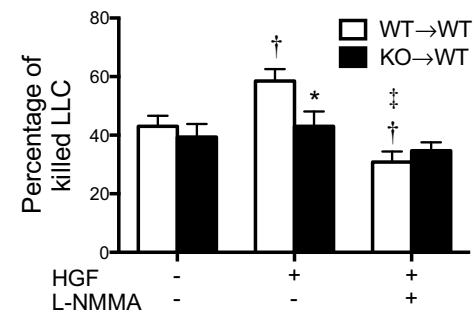

m

Circulating neutrophils

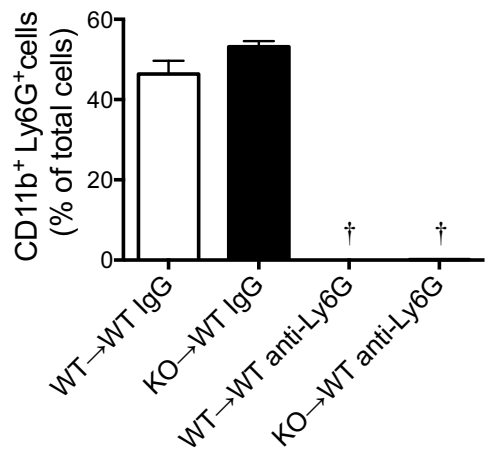


Extended Data Figure 8 $\mid$ MET affects neither neutrophil basal migration nor polarization but it is required for neutrophil recruitment and cytotoxicity. a, Quantification of Ly6G staining in ear sections upon phorbol ester (TPA)-induced cutaneous rash in Mrp8;Met $t^{w t / w t}$ and Mrp8;Met $t^{f / f l}$ mice. Data combine two independent experiments; total $n=8$ mice per condition. b, FACS analysis on peritoneal lavages for $\mathrm{Ly}_{6 \mathrm{G}}{ }^{+}$neutrophils or $\mathrm{F} 4 / 80^{+}$ macrophages in Mrp8;Met $t^{w t / w t}$ and Mrp8;Met $t^{f l f l}$ mice $4 \mathrm{~h}$ after intraperitoneal injection of sterile zymosan A. Data are representative of two independent experiments using 5 mice per condition per experiment. c, d, Quantification of F4/80 (c) and CD3 (d) stainings in ear sections at baseline and upon TPA-induced cutaneous rash. Data combine two independent experiments; total $n: \mathrm{WT} \rightarrow \mathrm{WT}$ control (CTRL), 22; KO $\rightarrow \mathrm{WT}$ CTRL, 15 ; WT $\rightarrow$ WT TPA, 23; KO $\rightarrow$ WT TPA, 15 (c); or total $n=8$ mice per condition (d). e, FACS quantification of Mrp8;Met $t^{w / w t}$ and Mrp8;Met $t^{f l / f t}$ neutrophils recruited into subcutaneous air pouches in response to HGF, CXCL1 or PBS. Data combine two independent experiments; total $n=6$ mice per condition. $\mathbf{f}$, FACS quantification of WT neutrophil adhesion to quiescent HUVECs (HUVEC/NS) or activated HUVECs (HUVEC/IL) in the presence or absence of HGF. Data are representative of two independent experiments using four biological replicates per condition per experiment. $\mathbf{g}, \mathbf{h}$, FACS quantification of WT and Met KO neutrophils migrated through a bare porous filter (that is, in the absence of HUVECs) towards HGF (g) or tumour conditioned medium (TCM) (h). Data are representative of two independent experiments using three biological replicates per condition per experiment. i, Gene expression profile for $\mathrm{N} 1$ and $\mathrm{N} 2$ markers in neutrophils sorted from LLC tumours grown in $\mathrm{WT} \rightarrow \mathrm{WT}$ or $\mathrm{KO} \rightarrow \mathrm{WT}$ mice. Data are representative of three independent experiments using 4 mice per condition per experiment. $\mathbf{j}$, Cytotoxicity of $\mathrm{WT}$ and $\mathrm{KO}$ tumour-associated neutrophils against T241 cells in the absence or presence of the NO synthase inhibitor L-NMMA. Data are representative of three independent experiments using three biological replicates per condition per experiment. k, FACS quantification of DAF-FM-positive circulating neutrophils after co-culture with LLC cancer cells as a readout of NO production in the absence or presence of HGF. Data are representative of four independent experiments using three biological replicates per condition per experiment. 1, Quantification of LLC cancer cell killing by WT and KO neutrophils (isolated from the blood of tumour-bearing mice), stimulated with HGF alone or in the presence of L-NMMA. Data are representative of two independent experiments using $n=12$ biological replicates per condition per experiment. $\mathbf{m}$, Blood neutrophils in $\mathrm{WT} \rightarrow \mathrm{WT}$ and $\mathrm{KO} \rightarrow \mathrm{WT}$ mice treated with neutrophildepleting Ly6G antibody or rat IgG as control. Data combine two independent experiments; total $n=16$ per condition. ${ }^{*} P<0.05$ versus $\operatorname{Mrp} 8 ; \operatorname{Met}^{w t / w t}(\mathbf{a}, \mathbf{b})$, versus Mrp8;Met $t^{w t / w t}+\operatorname{HGF}(\mathbf{e})$, versus HUVEC/ NS (f), versus $\mathrm{WT} \rightarrow \mathrm{WT}$ untreated $(\mathbf{j})$, versus $\mathrm{WT} \rightarrow \mathrm{WT}+\mathrm{HGF}$ $(\mathbf{k}, \mathbf{l}) ; \uparrow P<0.05$ versus CTRL (c, d), versus PBS (e), versus mock $(\mathbf{f}, \mathbf{h})$, versus $\mathrm{WT} \rightarrow \mathrm{WT}$ untreated $(\mathbf{j}-\mathbf{l})$, versus $\operatorname{IgG}(\mathbf{m}) ; \ddagger P<0.05$ versus $\mathrm{WT} \rightarrow \mathrm{WT}+\mathrm{HGF}(\mathbf{l})$. All graphs show mean \pm s.e.m. 
Extended Data Table 1 | Blood count in Tie2;Met ${ }^{w t / w t}$ or Tie2; Met $t^{f l / f l}$ tumour-free mice

\begin{tabular}{lcc}
\hline \hline Tumour free & Tie2; Met $^{\text {wt/wt }}$ & Tie2; Met flfl \\
\hline \hline WBC $(\mathrm{k} / \mu \mathrm{l})$ & $5.68 \pm 1.44$ & $5.55 \pm 1.29$ \\
NEU $(\%)$ & $23.03 \pm 5.45$ & $29.67 \pm 7.88$ \\
LYM (\%) & $69.72 \pm 6.46$ & $72.03 \pm 4.89$ \\
MON (\%) & $1.24 \pm 0.37$ & $2.86 \pm 1.15$ \\
EOS $(\%)$ & $0.12 \pm 0.05$ & $0.17 \pm 0.12$ \\
BAS $(\%)$ & $3.38 \pm 1.32$ & $4.47 \pm 2.1$ \\
RBC $(\mathrm{M} / \mu \mathrm{L})$ & $5.21 \pm 1.91$ & $4.89 \pm 1.52$ \\
HCT $(\%)$ & $71.3 \pm 3.43$ & $60.2 \pm 13.38$ \\
MCHC $(\mathrm{g} / \mathrm{dl})$ & $15.83 \pm 2.65$ & $18.3 \pm 0.26$ \\
PLT $(\mathrm{K} / \mu \mathrm{L})$ & $439.73 \pm 26.64$ & $508 \pm 55.79$ \\
\hline
\end{tabular}

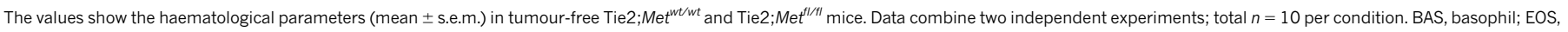
eosinophil; HCT, haematocrit; LYM, lymphocyte; MCHC, mean cell haemoglobin concentration; MON, monocyte; NEU, neutrophil; PLT, platelet; RBC, red blood cell; WBC, white blood cell. 


\section{RESEARCH LETTER}

Extended Data Table 2 | Blood count in WT $\rightarrow$ WT and $\mathrm{KO} \rightarrow \mathrm{WT}$ tumour-free or tumour-bearing mice

\begin{tabular}{|c|c|c|}
\hline Tumour free & $\mathbf{W T} \rightarrow \mathbf{W T}$ & $\mathrm{KO} \rightarrow \mathrm{WT}$ \\
\hline WBC $(\mathrm{k} / \mu \mathrm{l})$ & $10.03 \pm 2.05$ & $8.66 \pm 0.93$ \\
\hline NEU (\%) & $9.18 \pm 2.1$ & $10.3 \pm 3.07$ \\
\hline LYM (\%) & $85.2 \pm 2.91$ & $83.94 \pm 3.46$ \\
\hline MON (\%) & $1.41 \pm 0.48$ & $1.3 \pm 0.4$ \\
\hline EOS (\%) & $0.44 \pm 0.17$ & $0.25 \pm 0.05$ \\
\hline BAS (\%) & $3.77 \pm 0.68$ & $4.21 \pm 0.18$ \\
\hline $\mathrm{RBC}(\mathrm{M} / \mu \mathrm{L})$ & $8.21 \pm 0.54$ & $9.3 \pm 0.21$ \\
\hline HCT (\%) & $59.86 \pm 3.52$ & $70.16 \pm 1.67$ \\
\hline $\mathrm{MCHC}(\mathrm{g} / \mathrm{dl})$ & $18.63 \pm 0.61$ & $13.4 \pm 0.16$ \\
\hline $\operatorname{PLT}(\mathrm{K} / \mu \mathrm{L})$ & $589.26 \pm 134.65$ & $758.4 \pm 50.63$ \\
\hline Tumour bearing & WT $\rightarrow$ WT & $\mathrm{KO} \rightarrow \mathrm{WT}$ \\
\hline WBC $(\mathrm{k} / \mu \mathrm{l})$ & $7.97 \pm 0.63$ & $9.12 \pm 1.22$ \\
\hline NEU (\%) & $44.3 \pm 0.37$ & $53.71 \pm 7.23$ \\
\hline LYM (\%) & $27.29 \pm 8.33$ & $33.96 \pm 2.52$ \\
\hline MON (\%) & $1.79 \pm 0.75$ & $1.9 \pm 0.64$ \\
\hline EOS (\%) & $0.26 \pm 0.03$ & $0.45 \pm 0.1$ \\
\hline BAS (\%) & $1.94 \pm 0.53$ & $1.84 \pm 0.57$ \\
\hline $\mathrm{RBC}(\mathrm{M} / \mu \mathrm{L})$ & $5.5 \pm 0.54$ & $6.83 \pm 0.46$ \\
\hline HCT (\%) & $42.13 \pm 2.93$ & $49.43 \pm 3.47$ \\
\hline $\mathrm{MCHC}(\mathrm{g} / \mathrm{dl})$ & $18.27 \pm 0.5$ & $19.24 \pm 0.05$ \\
\hline $\operatorname{PLT}(\mathrm{K} / \mu \mathrm{L})$ & $566.17 \pm 109.48$ & $805.5 \pm 88.19$ \\
\hline
\end{tabular}

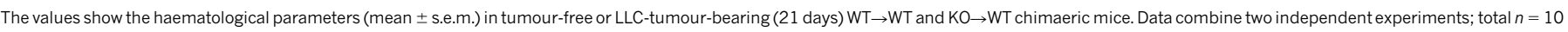

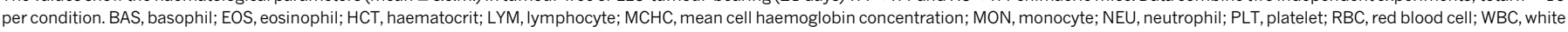
blood cell. 